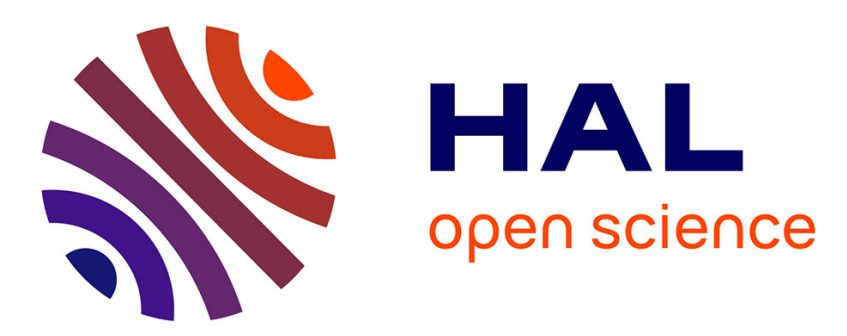

\title{
Insights on the synthesis mechanism of green phenolic resin derived porous carbons via a salt-soft templating approach
}

Cristina Nita, Mahmoud Bensafia, Cyril Vaulot, Luc Delmotte, Camelia Matei Ghimbeu

\section{To cite this version:}

Cristina Nita, Mahmoud Bensafia, Cyril Vaulot, Luc Delmotte, Camelia Matei Ghimbeu. Insights on the synthesis mechanism of green phenolic resin derived porous carbons via a salt-soft templating approach. Carbon, 2016, 109, pp.227-238. 10.1016/j.carbon.2016.08.011 . hal-02465100

\author{
HAL Id: hal-02465100 \\ https://hal.science/hal-02465100
}

Submitted on 7 Feb 2020

HAL is a multi-disciplinary open access archive for the deposit and dissemination of scientific research documents, whether they are published or not. The documents may come from teaching and research institutions in France or abroad, or from public or private research centers.
L'archive ouverte pluridisciplinaire HAL, est destinée au dépôt et à la diffusion de documents scientifiques de niveau recherche, publiés ou non, émanant des établissements d'enseignement et de recherche français ou étrangers, des laboratoires publics ou privés. 


\title{
Insights on the synthesis mechanism of green phenolic resin derived porous carbons via a salt-soft templating approach
}

\author{
Cristina Nita ${ }^{\mathrm{a}, \mathrm{b}}$, Mahmoud Bensafia ${ }^{\mathrm{a}, \mathrm{c}}$, Cyril Vaulot ${ }^{\mathrm{a}}$, Luc Delmotte ${ }^{\mathrm{a}}$, \\ Camelia Matei Ghimbeu ${ }^{\text {a, * }}$ \\ a Université de Strasbourg, Université de Haute Alsace, Institut de Science des Matériaux de Mulhouse, CNRS UMR 7361, 15 rue Jean Starcky, 68057 \\ Mulhouse, France \\ ${ }^{\mathrm{b}}$ National Institute for Lasers, Plasma and Radiation Physics, Atomistilor 409 bis, RO-77125 Magurele, Romania \\ ${ }^{\mathrm{c}}$ Université de Strasbourg, UFR Physique, 3-5 Rue de l'Université, F-67081 Strasbourg, France
}

\begin{abstract}
A B S T R A C T
A combined salt-soft template approach to synthesize porous carbon materials is reported along with their synthesis mechanism. This consists in the evaporation induced self-assembly (EISA) of aqueous solutions containing green phenolic resins, a triblock copolymer template and a metallic salt, followed by thermal treatment and washing. The increase of $\mathrm{pH}$ up to 5 using $\mathrm{NaOH}$, induces significant improvement in the carbon microporosity but in the detrimental of mesoporosity. As suggest by ${ }^{13} \mathrm{C}$ and ${ }^{1} \mathrm{H}$ NMR, the mesoporosity lost is caused by the decrease of $\mathrm{H}$-bonding and self-assembly between the phenolic resin and the template due to the strong "salting-out" effect of $-\mathrm{OH}$ ions. For higher $\mathrm{pH}$ (pH-9), the porosity start to decrease and graphene-sheet like morphology is formed. The microporosity varies with the salt in the following order: $\mathrm{KCl}>\mathrm{NaCl}>\mathrm{LiCl}$, while the mesoporosity in the opposite way. The structure changes as well from smooth turbostatic $(\mathrm{KCl})$ to defective graphitic one $(\mathrm{NaCl}, \mathrm{LiCl})$. These textural and structural modifications are explained in terms of cation hydration enthalpy and cation- $\pi$ binding energy and by the competition between the metal salt cations and the $\mathrm{Na}$ ions (used to regulate the $\mathrm{pH}$ ) for water or phenolic resin aromatic ring sites.
\end{abstract}

\section{Introduction}

Porous carbon materials are widely used in many fields of applications such as gas adsorption and separation, catalysis, water purification and energy storage [1-6]. Particularly, ordered mesoporous carbons (OMC) become very attractive owing to their controlled uniform pore size distribution, pore connectivity and large variety of pore and particle morphology [4]. The design of such materials can be achieved mainly by two synthetic approaches, i.e., hard-template (nanocasting) or soft-template. In the hard-template approach, a mesoporous silica template is usually used and infiltrated by a carbon precursor followed by thermal treatment and etching of silica with strong acids or bases [7-9]. The multistep reaction synthesis involving hazardous products is regarded as a limitation of this approach. Therefore, the softtemplate method, more recently developed, seems more promising due to the limited steps involved, easiness of preparation and large choice of synthesis parameters allowing to obtain carbon materials with various features [10-12]. In such approach, thermosetting phenolic resins are self-assembled with an amphiphilic triblock copolymer template via hydrogen or covalent bonding. A thermal treatment allows to decompose the phenolic resin and the template leading to the formation of a mesoporous carbon. Usually, phenol-formaldehyde resins are employed as carbon source in majority of published works [11], even if they are known to be carcinogen. Recently, we have proposed as a substituent of formaldehyde, a plant derived aldehyde, i.e., glyoxylic acid, which play a role of cross-linker and catalyst due to its double functionality (aldehyde/carboxylic acid), hence, the use of strong acids is not longer required as well [13]. Despite the large pallet of parameters that can be varied in soft-template approach, carbon materials with specific area higher than $\sim 700-800 \mathrm{~m}^{2} / \mathrm{g}$ is still difficult to achieve, and, in the same time, very challenging [14-18].

Several ways were proposed to overcome this inconvenient. Firstly, the classical activation route of carbon in gas phase $\left(\mathrm{H}_{2} \mathrm{O}\right.$ 
vapor, $\left.\mathrm{CO}_{2}\right)$ or with chemical reagents $\left(\mathrm{KOH}, \mathrm{H}_{3} \mathrm{PO}_{4} \ldots\right)$ may be used with success and, in some cases, the mesoporosity may be even preserved $[19,20]$. The main limitation of such route is related to the consumption of carbon, hence the low yield of reaction. Alternative ways to improve the surface area by using supplementary sacrificial template such as colloidal silica or by employing laboratory made templates have been also reported [21-24].

Recently, a salt-template route was proposed by Mokaya and Antonietti $[25,26]$ for the preparation of micro/mesoporous materials. A carbon source is mixed with a salt followed by thermal treatment and washing to remove the salt template. The advantage of such method is motivated by the use of cheap salts, which can be in addition recovered in the end of synthesis, but also by the high yield of obtained carbon compared with activation routs. Mostly, inorganic salt were used $\left(\mathrm{KCl}, \mathrm{LiCl}, \mathrm{CaCl}_{2}, \mathrm{ZnCl}_{2}, \mathrm{NaCO}_{3}\right.$ or their mixture), but some works using organic salt (potassium oxalate) were as well reported [26]. As carbon source, glucose was the most employed, but ionic liquids, phenolic resins or chitosan were used as well [25-32]. The increase of the temperature and the amount of salt prove to be important parameters to increase the carbon textural features. Therefore, materials with developed microporosity/mesoporosity up to $2100 \mathrm{~m}^{2} \mathrm{~g}^{-1}$ specific surface area and $1.5 \mathrm{~cm}^{3} \mathrm{~g}^{-1}$ porous volumes could be obtained [30]. By combining the salt template with hard template approach, impressive total porous volume (up to $4.3 \mathrm{~cm}^{3} / \mathrm{g}$ ) could be reached as well [27]. However, in none of these works the synthesis mechanism was discussed.

The aim of this paper is to combine the salt and soft template approaches in order to obtain high surface area carbon materials with various textural features. A second goal is to understand the synthesis mechanism of self-assembly of phenolic resins in the presence of organic templates, alkaline salts and bases and their effects on the textural, structural and morphological features of derived carbons. To our knowledge, such complex synthesis mechanisms were not addressed up to now. For this aim, green phenolic resins based on phloroglucinol/glyoxylic acid are employed together with a triblock polymer template to create the mesoporosity and several salts $(\mathrm{KCl}, \mathrm{NaCl}$ and $\mathrm{LiCl})$ to improve the microporosity. The influence of type of salt, $\mathrm{pH}$ of the solution and thermal treatment temperature on the carbon and phenolic resins characteristics were studied in detail. A synthesis mechanism is proposed based on ${ }^{13} \mathrm{C}$ and ${ }^{1} \mathrm{H}$ NMR at high and low fields, TGA and TEM analysis.

\section{Experimental part}

\subsection{Material synthesis}

Triblock copolymer Pluronic F127 [poly (ethylene oxide)blockpoly(propylene oxide)-block-poly-(ethylene oxide, $\mathrm{PEO}_{106} \mathrm{P}$ $\left.\left.\mathrm{PO}_{70} \mathrm{PEO}_{106}, \mathrm{Mw}=12,600 \mathrm{Da}\right)\right]$, phloroglucinol (1,3,5-benzentriol, $\left.\mathrm{C}_{6} \mathrm{H}_{6} \mathrm{O}_{3}\right)$, glyoxylic acid monohydrate $\left(\mathrm{C}_{2} \mathrm{H}_{2} \mathrm{O}_{3} \cdot \mathrm{H}_{2} \mathrm{O}\right)$, absolute ethanol $\left(\mathrm{C}_{2} \mathrm{H}_{6} \mathrm{O}\right)$, potassium chloride $(\mathrm{KCl})$, sodium chloride $(\mathrm{NaCl})$ and lithium chloride $(\mathrm{LiCl})$ were purchased from Sigma -Aldrich. Carbon materials were prepared by soft-template method involving phloroglucinol and glyoxylic acid as carbon precursors with a triblock copolymer template Pluronic F127, followed by thermal treatment. In a typical synthesis, phloroglucinol (0.83 g), glyoxylic acid (0.78 g) and pluronic F127 (1.6 g) were dissolved at room temperature in $10 \mathrm{ml}$ of ethanol, followed by the addition of $20 \mathrm{ml}$ of water. Then, the $\mathrm{KCl}$ metallic salt was dissolved in $10 \mathrm{ml}$ of water, added in the first solution and further mixed together for $30 \mathrm{~min}$. The molar ratio between the phenolic resin and the salts was kept to $1: 2$. The $\mathrm{pH}$ of the obtained solution was $\sim 1$ and was tuned up to 9 using aqueous $\mathrm{NaOH}$ solution $(1.25 \mathrm{M})$. The as obtained solutions were casted into Petri dishes and evaporated in a fume-hood for $12 \mathrm{~h}$ according to the EISA method (evaporation induced self-assembly). Thermopolymerization was performed at $120^{\circ} \mathrm{C}$, for $12 \mathrm{~h}$, followed by a thermal treatment under argon up to $900{ }^{\circ} \mathrm{C}$ during $1 \mathrm{~h}(2 \mathrm{~K} / \mathrm{min}$ slope). The $\mathrm{KCl}$ salt was removed by washing with hot distilated water $\left(90^{\circ} \mathrm{C}, 4 \mathrm{~h}\right)$. The influence of several metallic salts $(\mathrm{NaCl}$ $\mathrm{KCl}$ and $\mathrm{LiCl})$, of $\mathrm{pH}(1,3,5$ and 9$)$, of thermal treatment temperature $\left(600^{\circ} \mathrm{C}, 750{ }^{\circ} \mathrm{C}\right.$ and $\left.900^{\circ} \mathrm{C}\right)$ on the carbon and phenolic resins materials characteristics was studied. Considering the complex reaction mixture, in order to discriminate between the effect of each component, several materials have been prepared in the absence of: salt (No salt), template (pH-1 NT, pH-5 NT), $\mathrm{NaOH}(\mathrm{pH}-1)$, salt and $\mathrm{NaOH}$ ( $\mathrm{pH}-1 \mathrm{NS})$. All synthesis parameters used are listed in Table 1 along with the nomination of the obtained corresponding materials.

\subsection{Material characterization}

Carbon textural properties were measured by nitrogen adsorption at $77 \mathrm{~K}$ using a Micromeritics ASAP 2420 instrument. Prior to the analysis, the materials were degassed overnight in vacuum at $300{ }^{\circ} \mathrm{C}$. The BET specific surface area (SSA) was calculated from the linear plot in the relative pressure range of $0.01-0.05$. The micropore volume $\left(\mathrm{V}_{\text {micro }}\right)$ was obtained using the DubininRadushkevich (DR) equation in the relative pressure interval $(\mathrm{P} /$ $\left.\mathrm{P}_{0}\right)$ from $10^{-4}$ to $10^{-2}$. The total pore volume $\left(V_{T}\right)$ was determined from the amount of nitrogen adsorbed at a relative pressure of 0.99 . The mesoporous volume $\left(\mathrm{V}_{\text {meso }}\right)$ was determined by subtracting the microporous volume form the total pore volume. The pore size distributions (PSD) were determined from the adsorption branch of nitrogen isotherms using the 2D NLDFT heterogeneous surface model for carbon materials implemented in SAIEUS (Micromeritics) $[33,34]$. The carbonaceous material morphology was evaluated by TEM with a JEOL, ARM-200F model instrument operating at $200 \mathrm{kV}$. The long-range ordering of the materials was studied by small angle X-Ray scattering (SAXS) analysis by a Rigaku SMax 3000 equipped with a rotating $\mathrm{Cu}$ anode Micromax- 007HF (40 kV, $30 \mathrm{~mA}$ ) and OSMIC CMF optics. Raman measurements were

Table 1

Synthesis conditions used for the preparation of carbon materials.

\begin{tabular}{llllll}
\hline Material & $\mathrm{pH}$ & Temperature & Salt & NaOH & Template \\
\hline $\mathrm{pH}-1 \mathrm{NS}$ & 1 & $900{ }^{\circ} \mathrm{C}$ & $\mathrm{No}$ & $\mathrm{No}$ & Yes \\
$\mathrm{pH}-1$ & 1 & $900{ }^{\circ} \mathrm{C}$ & $\mathrm{KCl}$ & No & Yes \\
$\mathrm{pH}-3$ & 3 & $900{ }^{\circ} \mathrm{C}$ & $\mathrm{KCl}$ & Yes & Yes \\
$\mathrm{pH}-5$ & 5 & $900{ }^{\circ} \mathrm{C}$ & $\mathrm{KCl}$ & Yes & Yes \\
$\mathrm{pH}-9$ & 9 & $900{ }^{\circ} \mathrm{C}$ & $\mathrm{KCl}$ & Yes & Yes \\
& & & & & \\
$\mathrm{No} \mathrm{salt}$ & 5 & $900{ }^{\circ} \mathrm{C}$ & - & Yes & Yes \\
$\mathrm{KCl}$ & 5 & $900{ }^{\circ} \mathrm{C}$ & $\mathrm{KCl}$ & Yes & Yes \\
$\mathrm{NaCl}$ & 5 & $900{ }^{\circ} \mathrm{C}$ & $\mathrm{NaCl}$ & Yes & Yes \\
LiCl & 5 & $900{ }^{\circ} \mathrm{C}$ & $\mathrm{LiCl}$ & Yes & Yes \\
& & & & & \\
$\mathrm{KCl}-600$ & 5 & $600{ }^{\circ} \mathrm{C}$ & $\mathrm{KCl}$ & Yes & Yes \\
$\mathrm{KCl}-750$ & 5 & $750{ }^{\circ} \mathrm{C}$ & $\mathrm{KCl}$ & Yes & Yes \\
$\mathrm{KCl}-900$ & 5 & $900{ }^{\circ} \mathrm{C}$ & $\mathrm{KCl}$ & Yes & Yes \\
& & & & & \\
LiCl-600 & 5 & $600{ }^{\circ} \mathrm{C}$ & $\mathrm{LiCl}$ & Yes & Yes \\
LiCl-750 & 5 & $750{ }^{\circ} \mathrm{C}$ & $\mathrm{LiCl}$ & Yes & Yes \\
LiCl-900 & 5 & $900{ }^{\circ} \mathrm{C}$ & $\mathrm{LiCl}$ & Yes & Yes \\
pH1-NT & 1 & $900{ }^{\circ} \mathrm{C}$ & $\mathrm{KCl}$ & No & No \\
pH5-NT & 5 & $900{ }^{\circ} \mathrm{C}$ & $\mathrm{KCl}$ & Yes & No \\
\hline
\end{tabular}


performed at room temperature in a backscattering geometry using a LabRAM BX40 (Horiba Jobin-Yvon) microspectrometer equipped with a $\mathrm{He}-\mathrm{Ne}$ excitation source (wavelength $532 \mathrm{~nm}$ ). The phenolic resin structure and the interactions with the template were studied by solid-state ${ }^{13} \mathrm{C}$ and ${ }^{1} \mathrm{H}$ magic angle spinning (MAS). NMR spectra were obtained at a frequency of $100.6 \mathrm{MHz}, 400.13 \mathrm{MHz}$ respectively on a Bruker Avance 400 NMR spectrometer. Supplementary details about the analysis may be found in the SI part. ${ }^{1} \mathrm{H}$ NMR relaxation experiments were performed for static samples in $9 \mathrm{~mm}$ NMR tubes on a Bruker Minispec MQ-20 spectrometer operating at a proton resonance frequency of $20 \mathrm{MHz}$. T1 experiments were carried on by inversion recovery sequence.

\section{Results}

\subsection{Carbon characterization}

\subsubsection{Influence of $\mathrm{pH}$}

The synthesis of carbon materials involves the self-assembly of green phenolic resin based on phloroglucinol/glyoxylic acid with a Pluronic F127 amphiphilic template in aqueous predominant medium. When the $\mathrm{KCl}$ is added in the mixture, the $\mathrm{pH}$ of overall solution is around $\sim 1$. The obtained carbon using such solution ( $\mathrm{pH}-1)$ is characterized by a type I/IV nitrogen adsorption/desorption isotherm (Fig. 1a) corresponding to a micro/mesoporous material. The high increase of adsorbed nitrogen amount in the low relative pressure region is associated with the formation of micropores induced by decomposition of phenolic resin. The observed $\mathrm{H} 3$ type hysteresis at higher relative pressures is related to the selfassembly of phenolic resin/template in macromolecular structure and further decomposition of the template with mesoporosity formation. The specific surface area is $538 \mathrm{~m}^{2} \mathrm{~g}^{-1}$ while the microporous and mesoporous volume are 0.21 and $0.31 \mathrm{~cm}^{3} \mathrm{~g}^{-1}$, respectively (Table 2). The pore size distribution (Fig. 1b) shows micropores centered on $0.6 \mathrm{~nm}$ and mesopores located around
Table 2

Textural characteristics of carbon materials obtained using different synthesis conditions.

\begin{tabular}{|c|c|c|c|c|}
\hline Material & 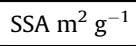 & $\mathrm{V}_{\mathrm{T}} \mathrm{cm}^{3} \mathrm{~g}^{-1}$ & $\mathrm{~V}_{\text {micro }} \mathrm{cm}^{3} \mathrm{~g}^{-1}$ & $\mathrm{~V}_{\text {meso }} \mathrm{cm}^{3} \mathrm{~g}^{-1}$ \\
\hline pH-1 NS & 535 & 0.37 & 0.20 & 0.17 \\
\hline $\mathrm{pH}-1$ & 538 & 0.52 & 0.21 & 0.31 \\
\hline $\mathrm{pH}-3$ & 911 & 0.46 & 0.36 & 0.10 \\
\hline $\mathrm{pH}-5$ & 1673 & 0.84 & 0.64 & 0.20 \\
\hline $\mathrm{pH}-9$ & 1557 & 0.76 & 0.60 & 0.16 \\
\hline No salt & 109 & 0.04 & 0.04 & 0.00 \\
\hline $\mathrm{KCl}$ & 1673 & 0.84 & 0.64 & 0.20 \\
\hline $\mathrm{NaCl}$ & 1449 & 0.75 & 0.55 & 0.20 \\
\hline $\mathrm{LiCl}$ & 1150 & 0.81 & 0.43 & 0.38 \\
\hline KCl-600 & 1005 & 0.48 & 0.39 & 0.09 \\
\hline $\mathrm{KCl}-750$ & 1383 & 0.64 & 0.54 & 0.10 \\
\hline KCl-900 & 1673 & 0.78 & 0.64 & 0.14 \\
\hline LiCl-600 & 567 & 0.41 & 0.23 & 0.18 \\
\hline LiCl-750 & 775 & 0.50 & 0.32 & 0.18 \\
\hline LiCl-900 & 1150 & 0.81 & 0.43 & 0.38 \\
\hline pH1-NT & 752 & 0.31 & 0.30 & 0.01 \\
\hline pH5-NT & 1815 & 0.76 & 0.73 & 0.03 \\
\hline
\end{tabular}

SSA-total specific surface area determined by the BET method.

$\mathrm{V}_{\mathrm{T}}, \mathrm{V}_{\text {micro }}$ and $\mathrm{V}_{\text {meso }}$ - total pore volume, micropore volume and mesopore volume.

7-8 $\mathrm{nm}$. The specific surface area and the microporous volume of pH-1 material are similar to that of carbon prepared in the absence of $\mathrm{KCl}$ ( $\mathrm{pH}-1 \mathrm{NS}$ ), however, the mesoporous volume is higher (see Table 2). This comparison ( $\mathrm{pH}-1$ and $\mathrm{pH}-1 \mathrm{NS}$ ) suggests that the $\mathrm{KCl}$ salt do not allow improving the microporosity in such conditions, therefore, the influence of $\mathrm{pH}$ was further investigated.

For $\mathrm{pH}$ comprised between 3 and 9, the hysteresis shape changes from type $\mathrm{H} 3$ to $\mathrm{H} 4$ type. When the $\mathrm{pH}$ increases from 1 to 3 , an increase of the specific surface area from $538 \mathrm{~m}^{2} \mathrm{~g}^{-1}$ to
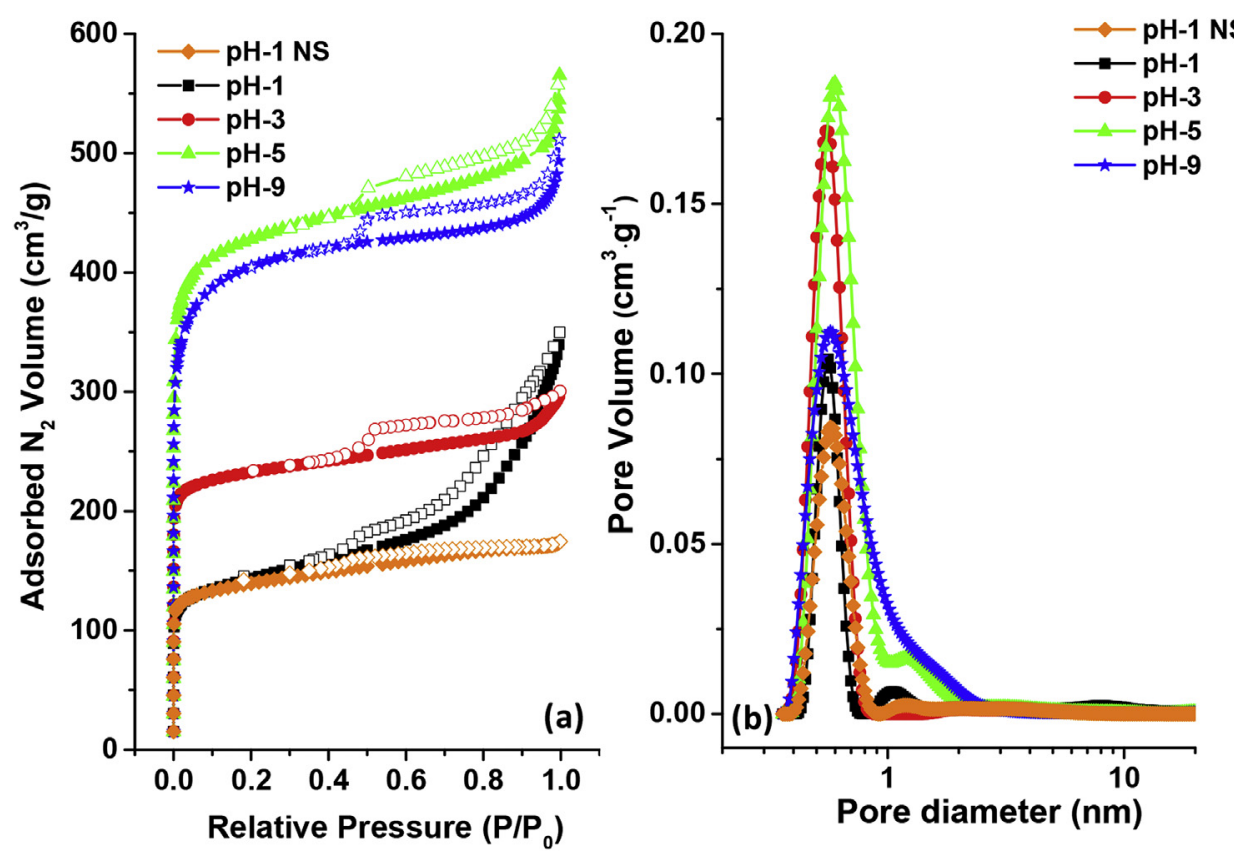

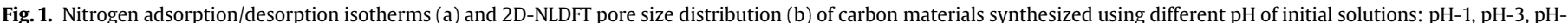

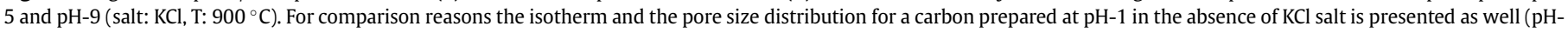
$1 \mathrm{NS}$ ). (A color version of this figure can be viewed online.) 
$911 \mathrm{~m}^{2} \mathrm{~g}^{-1}$ is obtained. The microporous volume is mainly improved from 0.21 to $0.36 \mathrm{~cm}^{3} \mathrm{~g}^{-1}$ in the detriment of mesoporous volume which diminishes from 0.31 to $0.10 \mathrm{~cm}^{3} \mathrm{~g}^{-1}$. Further increase of the $\mathrm{pH}$ to 5 allows to better improve the microporosity $\left(0.64 \mathrm{~cm}^{3} \mathrm{~g}^{-1}\right)$ and the surface area $\left(1673 \mathrm{~m}^{2} \mathrm{~g}^{-1}\right)$ (Table 2). However, if higher $\mathrm{pH}$ is used, the SSA and the porous volumes slightly decrease; a slight increase in the micropore size distribution may be observed as well with the $\mathrm{pH}$ increase (Fig. 1b).

The morphology of the materials obtained with different $\mathrm{pH}$ conditions was as well examined. The TEM pictures of $\mathrm{pH}-1$ material show an ordered hexagonal structure with parallel carbon channels and visible mesoporosity (Fig. 2a), in line with the adsorption results. The increase of the $\mathrm{pH}$ to 3 induces the formation of a disordered worm-like mesostructure (Fig. 2b) which disappears in the favor of a smooth microporous structure for $\mathrm{pH}-5$ (Fig. 2c). Interestingly, when the $\mathrm{pH}$ is 9 (Fig. 2d) porous sheets of carbon with graphitic/graphene aspect are obtained. Raman spectra performed in several places on this sample (see Fig. S1, Supporting Informations) show a disordered structure (D peak is higher than $G$ peak), but also the presence of the $G^{\prime}$ peak which originates from the staking of graphene sheets along the c-axis [35]. Hence, the $\mathrm{pH}$ greatly influences the textural, morphological and structural characteristics of derived carbons.

\subsubsection{Influence of type of salt}

As previously showed, the type of salt may alter the microporosity of the resulting carbon materials [25,27-32]. In the case of the soft-template synthesis, the salt modifies also the critical micellar concentration of the surfactant and, therefore, the selfassembly process and the polymerization rate of the phenolic resin.

Three salts were studied: $\mathrm{KCl}, \mathrm{NaCl}$ and $\mathrm{LiCl}$ and the $\mathrm{pH}-5$ allowing the obtain the highest surface area was selected. For comparison purposes one material was synthesized in the absence of any salt (No salt). The nitrogen adsorption/desorption isotherms and the pore size distribution of derived carbons are shown in Fig. 3.

When $\mathrm{KCl}$ and $\mathrm{NaCl}$ are used the isotherms are rather similar, while in the case of $\mathrm{LiCl}$ a lower adsorbed nitrogen quantity is noticed in the low relative pressure region. The surface areas are: 1673,1449 and $1150 \mathrm{~m}^{2} \mathrm{~g}^{-1}$ for $\mathrm{KCl}, \mathrm{NaCl}$ and $\mathrm{LiCl}$ derived materials, respectively (Table 2). The microporosity increases, therefore, in the following order $\mathrm{KCl}>\mathrm{NaCl}>\mathrm{LiCl}$, while the mesoporosity have an opposite behavior (see Table 2). If no salt is used, the textural properties are very low, a surface of only $109 \mathrm{~m}^{2} \mathrm{~g}^{-1}$ is reached.

This suggests on one hand that the salt play an important role on textural properties. On the other hand, if we compare the SSA of "no salt" material prepared in the absence of $\mathrm{NaOH}\left(109 \mathrm{~m}^{2} \mathrm{~g}^{-1}\right)$ with that of material obtained in acidic conditions, hence in the absence of $\mathrm{NaOH}\left(\mathrm{pH}-1 \mathrm{NS}, 535 \mathrm{~m}^{2} \mathrm{~g}^{-1}\right)$, lower textural properties are induce by the presence of $\mathrm{NaOH}$. Therefore, basic conditions are not favorable for the self-assembly of the phenolic resin with the template. The micropore size is mainly centered on $0.6 \mathrm{~nm}$ as seen in Fig. 3b.

In the absence of salt, the morphology (Fig. 4a) shows some irregulars mesopores. In the case of $\mathrm{KCl}$ the morphology is smooth (Fig. 4b), while for the $\mathrm{NaCl}$ and $\mathrm{LiCl}$ a sheet-like morphology is obtained (Fig. 4c-f).

Further insights on the carbon structure $v s$. the metal salt were assessed by Raman spectroscopy (Fig. 5). Several Raman spectra were taken in different zones of the materials and they present different ratio between the peak intensities or widths, suggesting heterogeneous structure in agreement with the TEM morphology. For clarity reasons, one representative spectrum for each material is shown (Fig. 5).

For $\mathrm{KCl}$, the spectra are characterized by two peaks placed at $1325 \mathrm{~cm}^{-1}$ and $1590 \mathrm{~cm}^{-1}$ which correspond to the $\mathrm{D}$ (defects) and $\mathrm{G}$ ( $\mathrm{Csp}^{2}$ graphite) bands, respectively. When $\mathrm{NaCl}$ is used, the peaks become narrow and a third peak placed at $2640 \mathrm{~cm}^{-1}$ appears which is related to the $\mathrm{G}^{\prime}$ band in graphite/graphene materials [36]. For $\mathrm{LiCl}$ the spectra looks similar to those of $\mathrm{NaCl}$. For all materials the $G$ band is more intense than the $D$ band indicating a certain degree of structural ordering. The absence of $G^{\prime}$ band and the broader peaks in $\mathrm{KCl}$ materials may lead to the conclusion that it
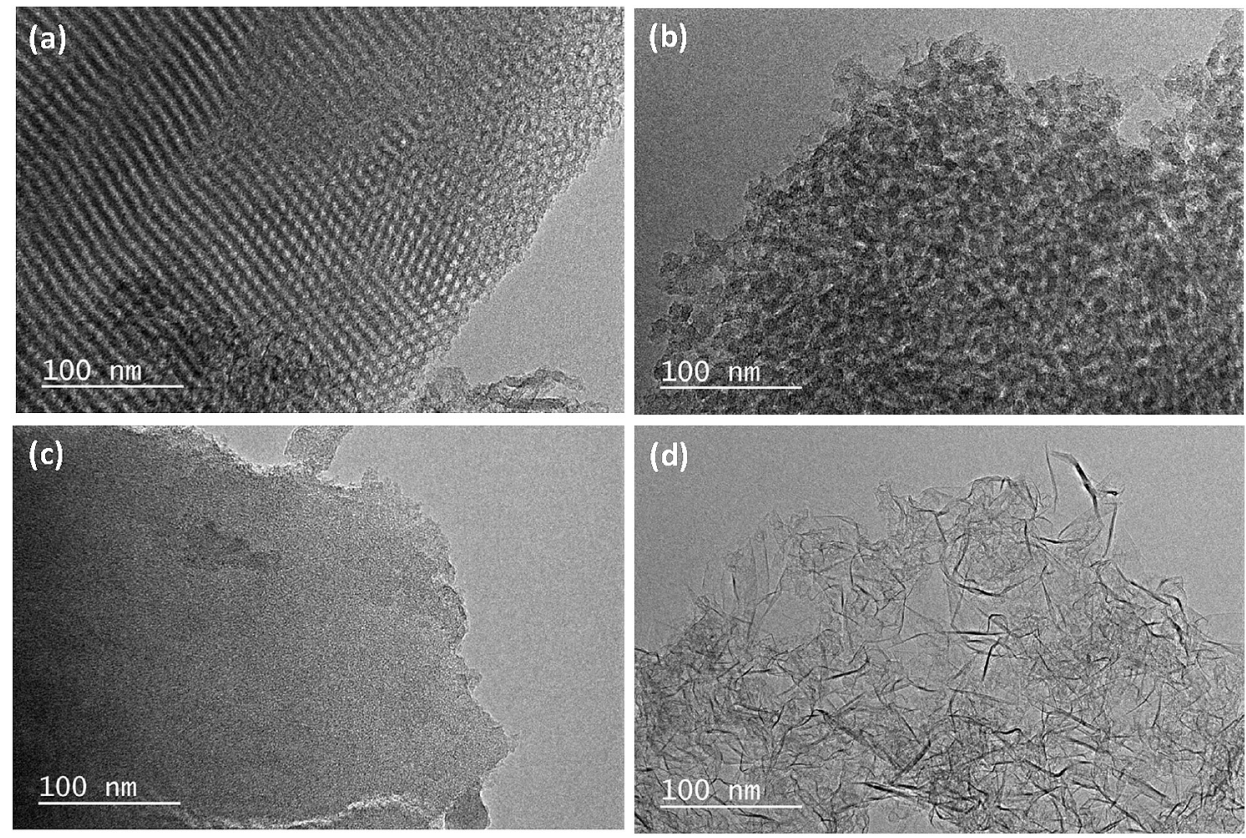

Fig. 2. TEM pictures of carbon materials synthesized using different $\mathrm{pH}$ of initial solutions: (a) $\mathrm{pH}-1$; (b) $\mathrm{pH}-3$; (c) $\mathrm{pH}-5$ and (d) $\mathrm{pH}-9$ (salt: $\mathrm{KCl}$, T: $900{ }^{\circ} \mathrm{C}$ ). 


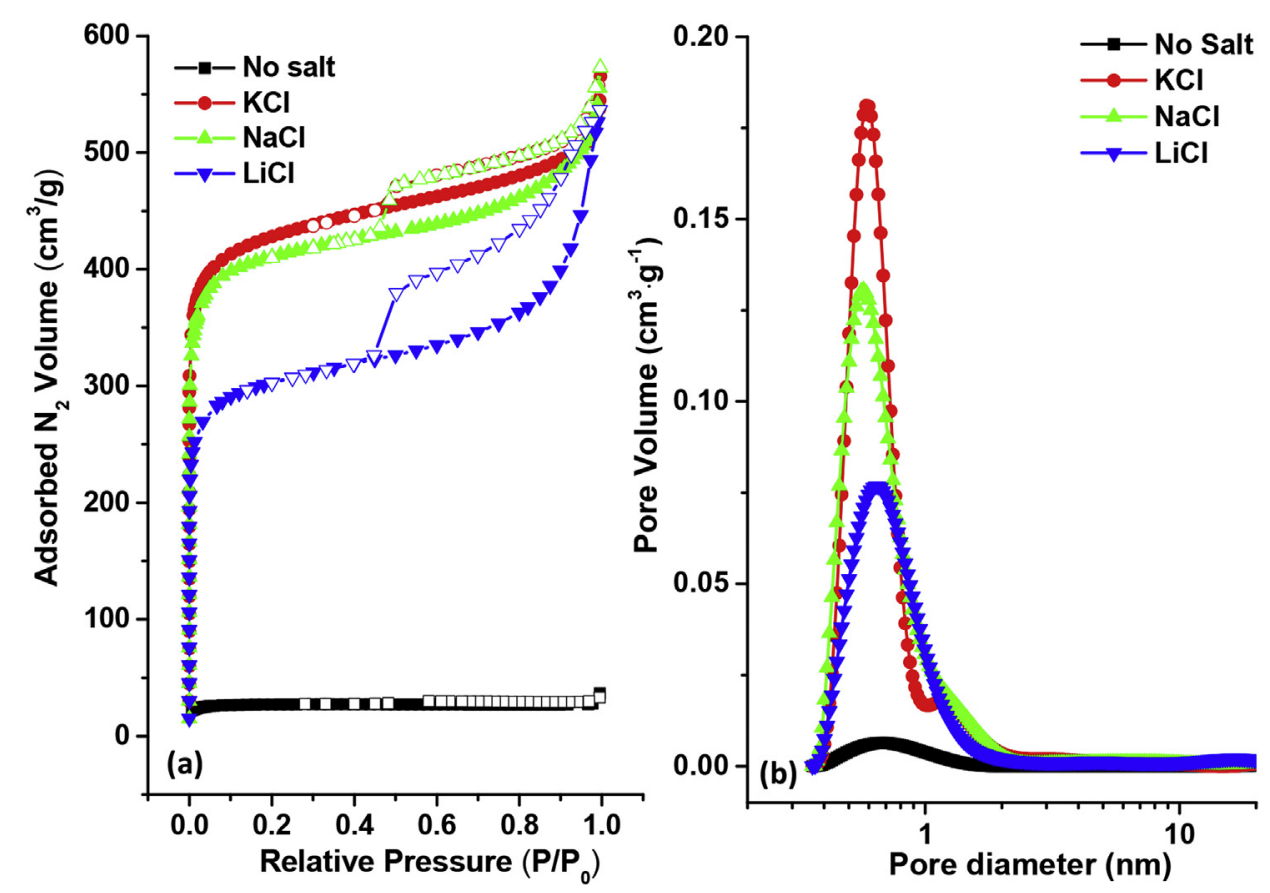

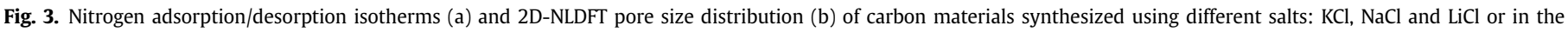
absence of salt; ( $\left.\mathrm{pH}-5, \mathrm{~T}: 900{ }^{\circ} \mathrm{C}\right)$. (A color version of this figure can be viewed online.)
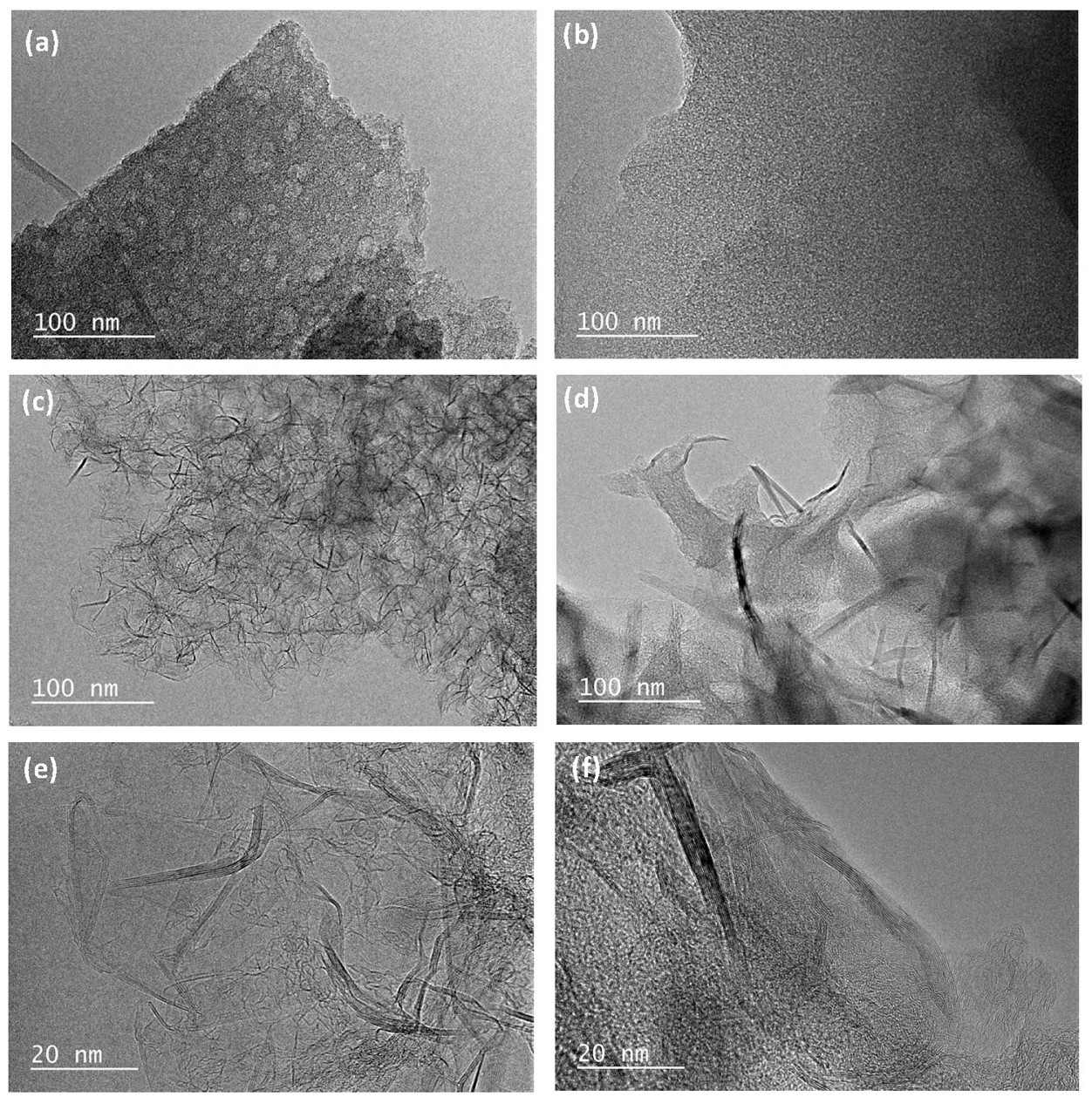

Fig. 4. TEM pictures of carbon materials synthesized (a) in the absence of salt or using different type of salts (b) $\mathrm{KCl}$ (c) $\mathrm{NaCl}$ and (d) $\mathrm{LiCl}$ and $\mathrm{HRTEM}$ of (e) $\mathrm{NaCl}$ and (f) $\mathrm{LiCl}$ carbons. 


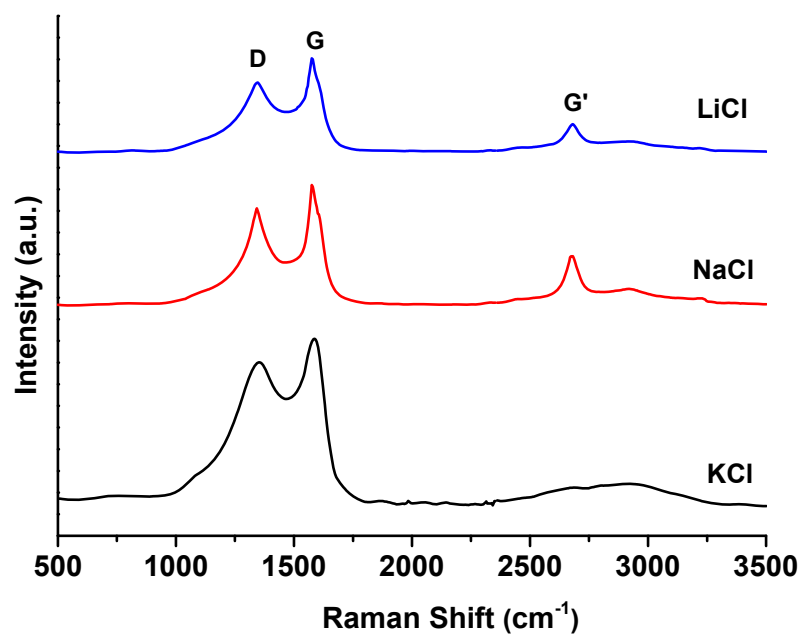

Fig. 5. Raman spectra of carbon materials synthesized in the presence of (a) $\mathrm{KCl}$; (b) $\mathrm{NaCl}$ and (c) $\mathrm{LiCl}\left(\mathrm{pH}-5 ; \mathrm{T}\right.$ : $900^{\circ} \mathrm{C}$ ). (A color version of this figure can be viewed online.)

exhibits the most disordered structure.

\subsubsection{Influence of thermal treatment temperature}

The influence of the thermal treatment temperature $\left(600{ }^{\circ} \mathrm{C}\right.$, $750{ }^{\circ} \mathrm{C}$ and $900{ }^{\circ} \mathrm{C}$ ) on the textural and structural properties of carbon materials was evaluated. Two salts giving significantly differences between textural properties at pH-5 (see Table 2) were selected for this study, i.e., $\mathrm{KCl}$ and $\mathrm{LiCl}$. The nitrogen adsorption/ desorption isotherms along with their pore size distribution are depicted in Fig. 6.

All materials prepared with $\mathrm{KCl}$ exhibit a type I isotherm (Fig. 6a) according to the IUPAC classification, characteristic to microporous materials. The increase of the thermal treatment temperature from $600{ }^{\circ} \mathrm{C}$ to $900{ }^{\circ} \mathrm{C}$ induces an increase in the adsorbed nitrogen quantity and consequently of the specific surface area and microporous volume, from 1005 to $1673 \mathrm{~m}^{2} \mathrm{~g}^{-1}$ and from 0.39 to $0.64 \mathrm{~cm}^{3} \mathrm{~g}^{-1}$, respectively. In addition, with the increase of the temperature some larger micropores $(1.2 \mathrm{~nm})$ are formed beside those at $0.6 \mathrm{~nm}$ (in-set Fig. 6a). Similar behavior was reported in other works using $\mathrm{CaCl}_{2}$ or $\mathrm{ZnCl}_{2}$ salts $[26,28]$. The mesopore volume is not varying up to $750^{\circ} \mathrm{C}$, and then an increase is observed for $900{ }^{\circ} \mathrm{C}$, from 0.10 to $0.14 \mathrm{~cm}^{3} \mathrm{~g}^{-1}$. The morphology it not changing with the temperature increase as demonstrated by TEM analysis (Fig. S2, SI).

The nitrogen adsorption/desorption isotherms for $\mathrm{LiCl}$ derived materials (Fig. 6b) show different shape compared to $\mathrm{KCl}$, i.e. type I/ IV which is characteristic to micro/mesoporous materials. However, the same evolution of textural vs. temperature as for $\mathrm{KCl}$ is observed, i.e., increase of the microporosity and mesoporosity with the temperature. The micropores sizes are centered around $0.6 \mathrm{~nm}$ (in-set Fig. 6b) while the mesopores around $50 \mathrm{~nm}$ as demonstrated by $\mathrm{BJH}$ pore size distribution (Fig. S3, SI). For LiCl, the temperature has an effect on the morphology/structure as well (see Fig. S4, SI). By increasing the temperature to $750^{\circ} \mathrm{C}$, graphitic-like sheets start to be formed as highlighted by TEM pictures and SAED (selectedarea electron diffraction).

\subsubsection{Influence of pluronic template}

The influence of pluronic template presence/absence in the synthesis mixture on the textural/structural properties at $\mathrm{pH} 1$ and 5 was investigated as well and the nitrogen adsorption/desorption isotherms are depicted in Fig. 7. In both $\mathrm{pH}$ cases, the presence/ absence of template do not significantly modifies the nitrogen adsorption in the low relative pressure region related to the micropores.

The use of the template plays an important role on the mesoporosity. In the case of $\mathrm{pH}-1$, a hysteresis associated with the condensation in the mesopores is observed (Fig. 7a). The mesoporous volume is significantly reduced from 0.31 to $0.20 \mathrm{~cm}^{3} \mathrm{~g}^{-1}$
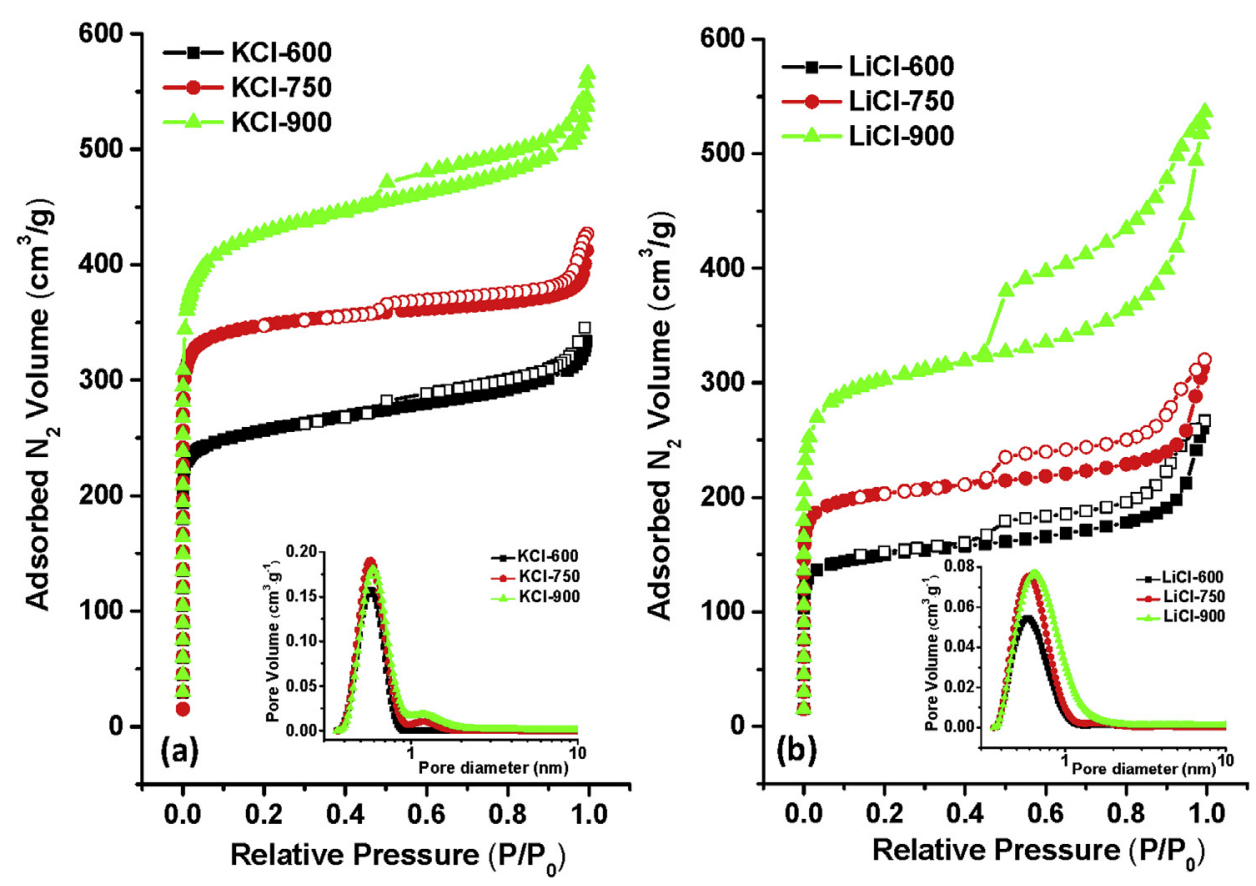

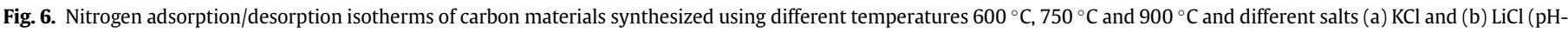
5); in-set: the corresponding 2D-NLDFT pore size distribution. (A color version of this figure can be viewed online.) 

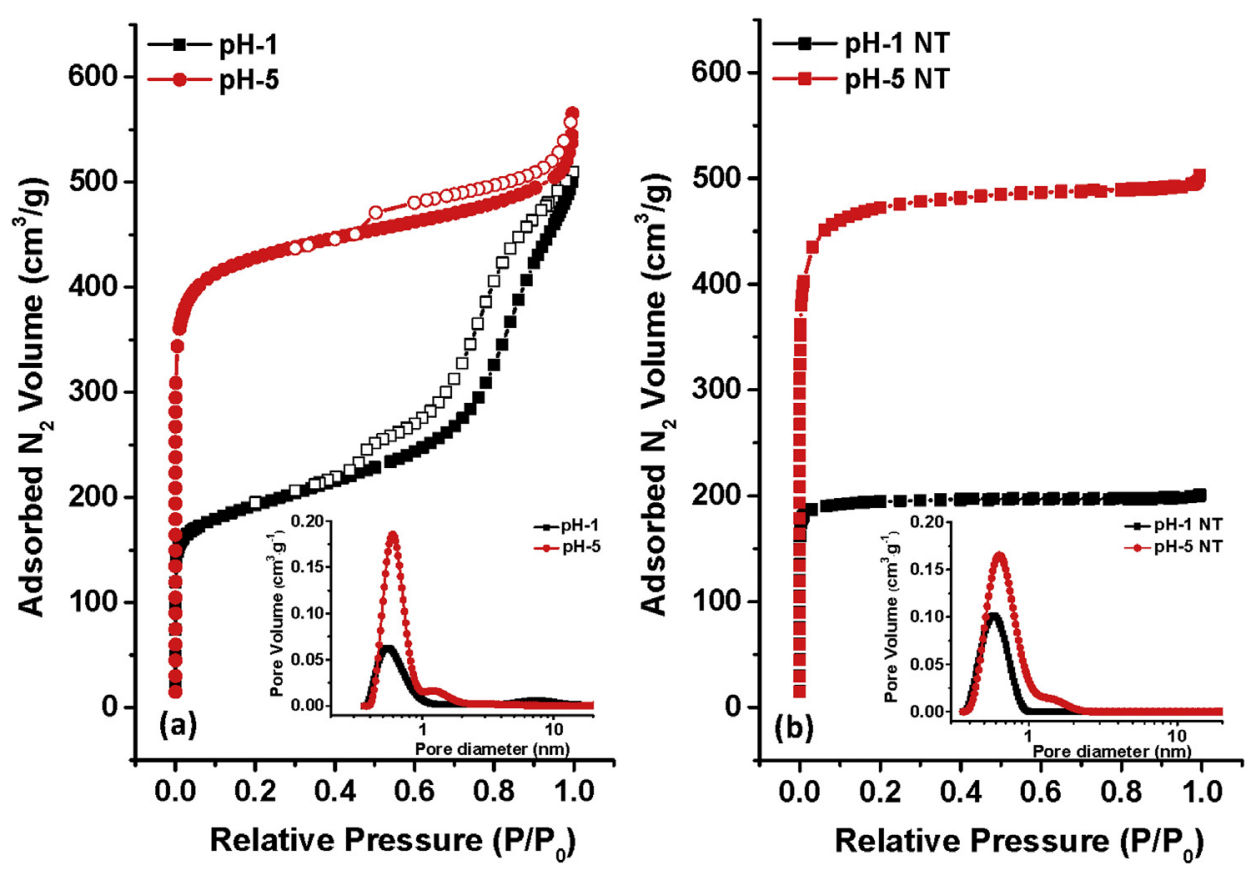

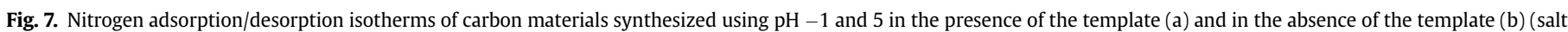
$\mathrm{KCl}, \mathrm{T}$ : $900{ }^{\circ} \mathrm{C}$ ); in-set: the corresponding 2D-NLDFT pore size distribution. (A color version of this figure can be viewed online.)

when the $\mathrm{pH}$ increases from 1 to 5 . This can be also visualized on the TEM pictures provided in Fig. S5, Supporting Informations.

In the absence of the template, perfectly type I isotherm specific to microporous materials with uniform small pore size distributions are obtained for $\mathrm{pH} 1$ (Fig. $7 \mathrm{~b}$ and $\mathrm{in}$-set), while for $\mathrm{pH}-5$ some larger micropore start to form (Fig. $7 \mathrm{~b}$ and in-set). The specific surface area and the microporous volumes are slightly higher in the absence of the template, i.e. 1815 vs. $1673 \mathrm{~m}^{2} \mathrm{~g}^{-1}$ for pH5-NT and $\mathrm{pH}-5$, respectively (Table 2 ).

In order to understand the formation of the microporosity/ mesoporosity the thermopolymerized phenolic resins were analyzed.

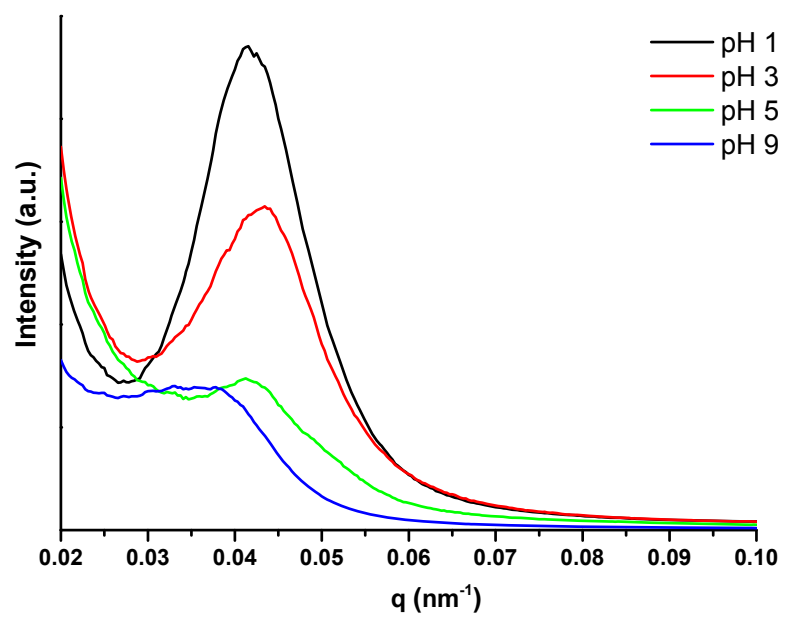

Fig. 8. (a) SAXS patterns of thermopolymerized phenolic resins prepared using different $\mathrm{pH}$ (salt $\mathrm{KCl}$, time: $1 \mathrm{~h}$ ). (A color version of this figure can be viewed online.)

\subsection{Characterization of the phenolic resin}

The images of petri dishes containing phenolic resins obtained with various $\mathrm{pH}$, dried at room temperature and further thermopolymerized at $120{ }^{\circ} \mathrm{C}$ are illustrated in Fig. S6 (Supporting Information). We can noticed that the color of the phenolic resin gradually shifts from colorless to dark orange when the $\mathrm{pH}$ changes from 1 to 9 (Fig. S6a-d). When the phenolic resins are thermopolymerized the color become dark-red no matter the $\mathrm{pH}$ used (Fig. S6e). This indicates oxidation of $-\mathrm{OH}$ groups and/or improve of crosslinking [37,38].

The SAXS patterns performed on thermopolymerized phenolic resins obtained with different $\mathrm{pH}$ conditions are shown in Fig. 8. One resolved peak placed at $\mathrm{q}=0.05 \mathrm{~nm}^{-1}$ which corresponds to the 10 diffraction planes of an ordered 2D hexagonal p6m mesostructure [39] is observed. The peak intensity decreases progressively with the increase of the pH from 1 to 9 , indicating the loss of mesoporosity ordering. This observation is in line with the TEM results on carbon materials (Fig. 2).

Further information about the structure of phenolic resins was assessed by solid state ${ }^{13} \mathrm{C}$ and ${ }^{1} \mathrm{H}$ NMR (Figs. 9 and 10). The ${ }^{13} \mathrm{C} \mathrm{CP}-$ MAS (cross-polarization magic angle spinning) NMR spectra for pH-1 reveal several resonance peaks as seen in Fig. 9a. For more details, the assignments of NMR peaks are listed in Table S1 (Supporting Information). The most intense peak is placed at $\sim 70 \mathrm{ppm}$ and can be attributed to the carbon atoms bonded with $\mathrm{O}$ atoms $\left(\mathrm{CH}_{2}-\mathrm{O}-\mathrm{CH}_{2}\right)$ in the PEO moieties of copolymer template Pluronic F127 [40]. The other less intense proximity peaks from $74-76$ ppm and from $18 \mathrm{ppm}$ are corresponding to the carbons involved in ethyl $\left(-\mathbf{C H}-\mathrm{CH}_{2}\right)$ and methyl $\left(-\mathrm{CH}_{3}\right)$ groups, respectively, of the PPO moieties of Pluronic F127 template [41].

Several peaks placed at 176, 155, 109, 98 and 39 ppm are related to the carbons involved in the phenolic resins formed via the polymerization reactions between the phloroglucinol and glyoxylic acid. More precisely, they can be assigned to the several structures labeled as A, $A^{\prime}$ and B in Eq. (2). As described in detail before [13] in 


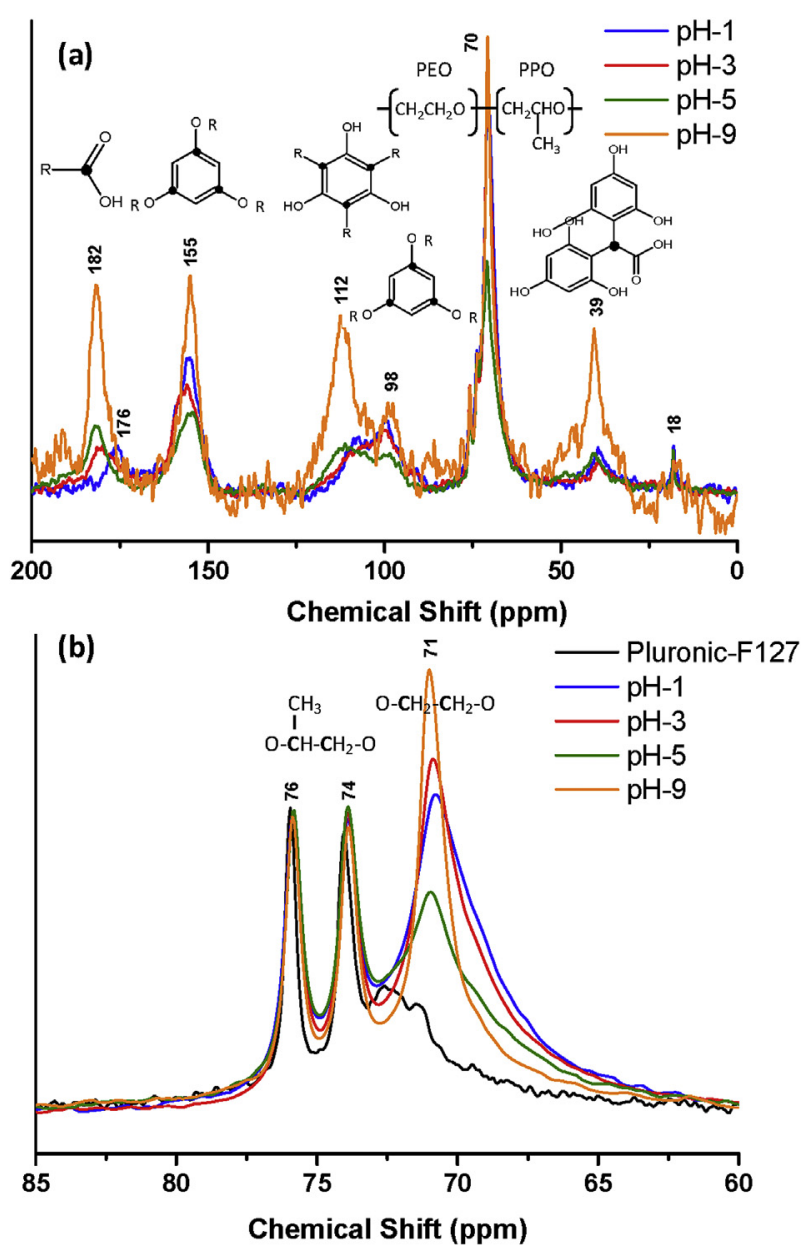

Fig. 9. (a) ${ }^{13} \mathrm{C} C P-M A S$ and (b) ${ }^{13} \mathrm{C}$ MAS-DEC solid-state NMR spectra of phenolic resins prepared using different $\mathrm{pH}$ conditions (salt $\mathrm{KCl}$ ). (A color version of this figure can be viewed online.) the first stages of reaction, the phloroglucinol and the glyoxylic acid react giving rise to the so-called trihydroxy phenylacetic acid (see Eq. (1)). The structures $A$ and $A^{\prime}$ are obtained via an electrophilic aromatic substitution reaction taking place between the trihydroxy phenylacetic acid and the phloroglucinol. Carboxylic acid bridges between the benzene rings are created and subsequent elimination of $\mathrm{H}_{2} \mathrm{O}$ molecules through the condensation of the carboxylic and hydroxyl group allow the formation of lactone groups and therefore, the A, $A^{\prime}$ tautomeric structures (Eq. (2)). The reaction between the trihydroxy phenylacetic acid and the phloroglucinol may also lead to structure B (Eq. (2)).

When the $\mathrm{pH}$ increases from 1 to 9 , the modification of peak intensity or/and position is clearly noticed. The peaks form $176 \mathrm{ppm}$ corresponding to the carbon atoms bonded with $\mathrm{O}$ in carboxylic acid group, shift to higher resonances (182 ppm). This may be explained by the formation of $\mathrm{R}-\mathrm{COONa}(\mathrm{K})$ species by deprotonation reactions of carboxylic acids groups in the presence of $\mathrm{NaOH}$, which are known to shift the ${ }^{13} \mathrm{C}$ NMR position. In addition, for $\mathrm{pH}-$ 9 significant increase in the intensity of $176 \mathrm{ppm}$ peak, as well as of the other peaks $(155,112,98$ and 39$)$ is observed. This maybe related to an increase of the cross-linking of polymer chains via the formation of highly substituted phloroglucinol compounds and other polymeric structures as discuss further.<smiles>Cc1cc(O)c(CC(=O)O)c(O)c1</smiles>

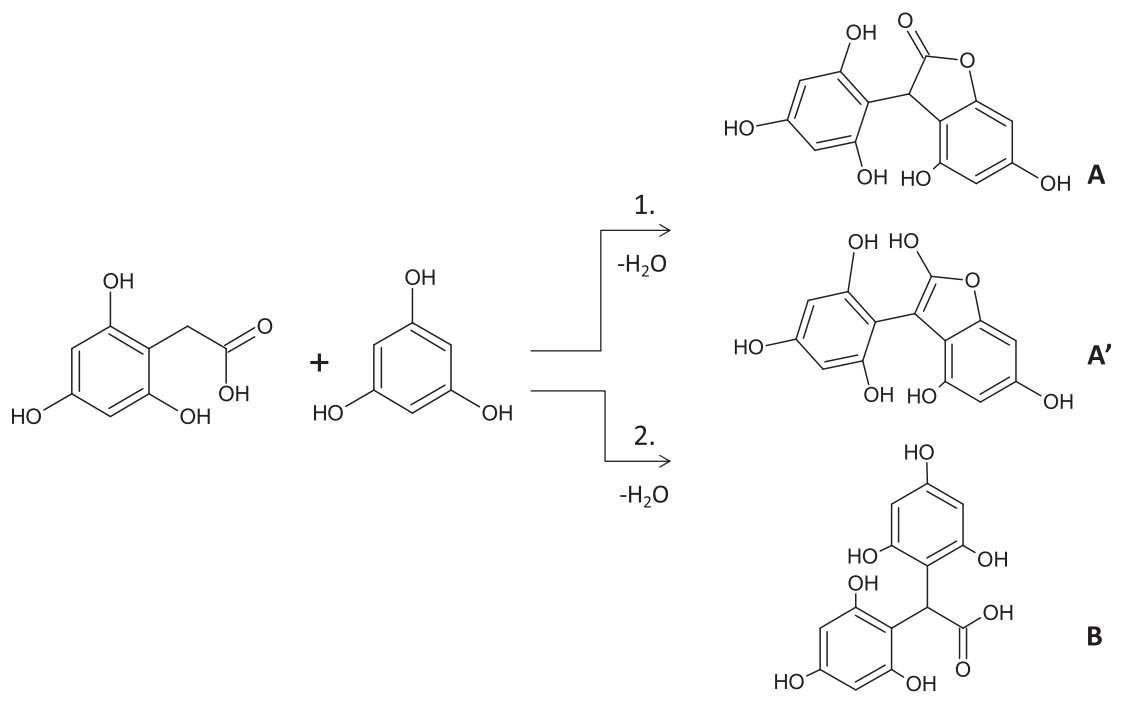




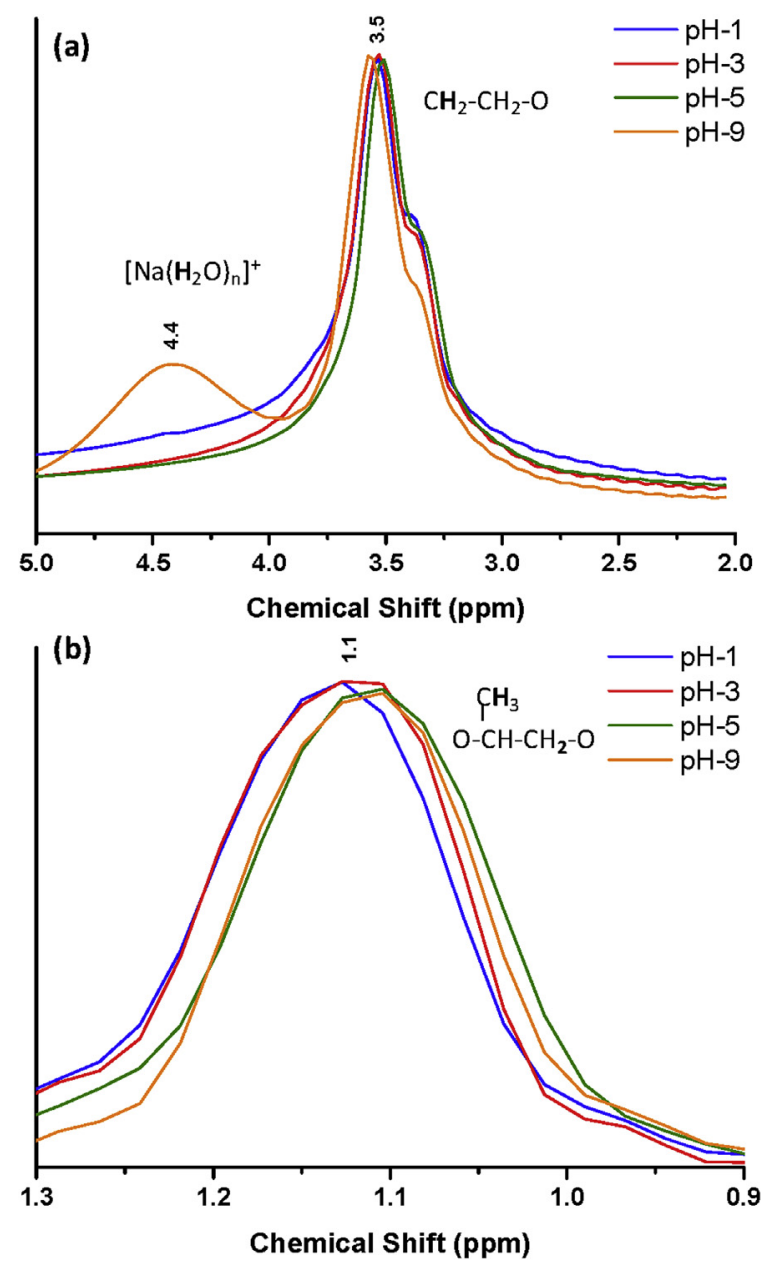

Fig. 10. ${ }^{1} \mathrm{H}$ solid state NMR spectra of phenolic resins prepared using different $\mathrm{pH}$ conditions (salt $\mathrm{KCl}$ ). (A color version of this figure can be viewed online.)

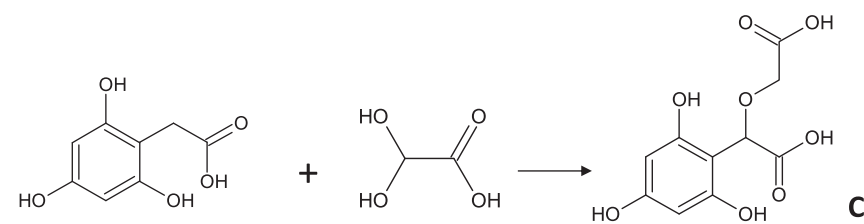

As the CP-MAS NMR is a technique very sensitive to rigid carbons (phloroglucinol-glyoxylic acid based phenolic resin), we further performed MAS-DEC (magic angle spinning decoupling) spectra to get more insights about the mobile part of the phenolic resin (pluronic F127 template). The MAS-DEC spectra are shown in Fig. 9b, and it can be seen that the peaks from 74, 76 ppm corresponding to the carbons in the hydrophobic PPO, are similar for all $\mathrm{pH}$ synthesized materials. On the contrary, the peak at $71 \mathrm{ppm}$ related to the carbon in the hydrophilic PEO fragments $\left(\mathrm{CH}_{2}-\mathrm{O}-\mathrm{CH}_{2}\right)$ is increasing with the increase of the $\mathrm{pH}$. The PEO/ PPO area ratio increases with the $\mathrm{pH}$ and is higher than the pure Pluronic template one. This may suggest on one hand the formation of other supplementary species containing $\mathrm{C}-\mathrm{O}-\mathrm{C}$ groups for instance due to reaction between the trihydroxy phenylacetic acid and the glyoxylic acid or between two trihydroxy phenylacetic acid structures as proposed in Eq. (3). On the other hand, this result implies a faster polymerization rate with the $\mathrm{pH}$ increase, in good agreement with the CP-MAS spectra. However, we noticed that $\mathrm{pH}-$ 5 behaves differently probably due to the fact that polymerization reactions are not favored for $\mathrm{pH}-5$, but rather in basic or acidic conditions.

Further insights on the chemical structure of these phenolic resins were assessed by ${ }^{1} \mathrm{H}$ NMR (Fig. 10a, b). Two NMR signals are noticed at $3.3 \mathrm{ppm}$ and $1.1 \mathrm{ppm}$, respectively, corresponding to protons in the ethylene oxides of PEO and propylene oxide of PPO moiety of the F127 surfactant [42]. In addition, for $\mathrm{pH}-9$, a peak at $4.4 \mathrm{ppm}$ is observed which was attributed to cations solvated by water (or "water structure"). In basic conditions, neutralization reaction between the acidic groups and the $\mathrm{NaOH}$ may take place giving rise to cations solvated by water $\left[\mathrm{Na}\left(\mathrm{H}_{2} \mathrm{O}\right)_{n}\right]$. Other origin of water structures may be the dehydration of PEO moieties in the presence of $\mathrm{NaOH}$ [43]. A competition between the $\mathrm{K}^{+}$and $\mathrm{Na}^{+}$ cations for water sites may occur in such conditions.

Regarding the peak placed at $1.1 \mathrm{ppm}$ ( $\mathrm{H}$ in PPO), a shift to lower frequency $(\sim 11 \mathrm{~Hz})$ is noticed for $\mathrm{pH}-5$ and $\mathrm{pH}-9$. This may be attributed to an aromatic ring current effect [44]. This suggests proximity of the hydrophobic PPO part of pluronic template with the aromatic planes the phenolic resin. In the case of $\mathrm{pH}-5$ and $\mathrm{pH}-9$ the phenolic resin is more cross-linked as determined by ${ }^{13} \mathrm{C}$ NMR, therefore, more aromatic sites are available.

The interactions between the phenolic resin and the template were studied by ${ }^{1} \mathrm{H}$ NMR at low fields. Fig. S7 (Supporting Informations) depicts the $\mathrm{T} 1$ relaxation curves for phenolic resins obtained using different $\mathrm{pH}$. Based on their behavior, the materials are separated into two groups, $\mathrm{pH}-1, \mathrm{pH}-3$ and $\mathrm{pH}-5, \mathrm{pH}-9$. The fit of these curves allows to distinguish a mono-component system for $\mathrm{pH}-1$ and $\mathrm{pH}-3$ materials ( $\mathrm{A} 1=100 \%$ ), while for $\mathrm{pH}-5$ and $\mathrm{pH}-9$ phenolic resins a bi-component system is determined (Table 3 ).

Consequently, for $\mathrm{pH}-1$ and $\mathrm{pH}-3$, one relaxation time is obtained (T1,1), indicating intimate interactions between the phenolic resin and the template. For instance, the self-assembly through $\mathrm{H}$ bonding between the oxygen of PPO and PEO segments of pluronic and $-\mathrm{OH}$ or $-\mathrm{COOH}$ groups of phenolic resin may be accounted for such behavior.

In the case of $\mathrm{pH}-5$ and $\mathrm{pH}-9$, two $\mathrm{T} 1$ are determined suggesting a bi-component system. The values for spin-lattice relaxation time, T1,1 decrease from 47.9 to $36.3 \mathrm{~ms}$ with the increase of the $\mathrm{pH}$ from 1 to 9 (Table 3). In addition, for pH-5 and pH-9, a supplementary T1 is determined, i.e., the spin-spin relaxation time (T1,2): 90.6 and $120.3 \mathrm{~ms}$, which is significantly much higher than T1,1 (38.4 and $36.3 \mathrm{~ms})$.

If $\mathrm{T} 1,2$ values are compared with those of pure pluronic F127 template, it can be seen that the T1,2 of pluronic is very closed to $\mathrm{T} 1,2$ of $\mathrm{pH}-5$ and $\mathrm{pH}-9$ which allow to attribute the A2 fraction to pluronic. This suggests that the pluronic template in the $\mathrm{pH}-5$ and pH-9 resins acts as a "free", therefore, a "separation" of the phenolic resins and the pluronic template occurred in such conditions explaining the loss of the auto-assembly and mesoporosity, in good agreement with the SAXS results.

To understand this "separation" between the phenol-resin and the template, the effects of salts and $\mathrm{NaOH}$ must be considered. The structure of PEO-PPO-PEO block copolymer micelles is described by a core-corona model, in which a spherical core is composed of PPO moieties surrounded by a corona of PEO strongly hydrated by water molecules [48]. The transformation of spherical micelles into worm-like micelles in the presence of $\mathrm{KCl}$ have been reported and explained by the dehydration of the PEO chains in the micelle corona [49] due to the increase of the water "structures" [43]. Water structure formation for $\mathrm{pH}-9$ materials have been demonstrated by ${ }^{1} \mathrm{H}$ NMR spectra (Fig. 10a). The self-assembly process and the organization of the micelles are particularly affected by the 
Table 3

${ }^{1} \mathrm{H}$ NMR relaxation parameters of phenolic resins obtained using different $\mathrm{pH}$.

\begin{tabular}{lllll}
\hline Materials & A1 $(\%)$ & T1,1 (ms) & A2 $(\%)$ & T1,2 (ms) \\
\hline pH-1 & 100 & 47.9 & - & - \\
pH-3 & 100 & 44.9 & - & - \\
pH-5 & 34 & 38.4 & 66 & 90.6 \\
pH-9 & 54 & 36.3 & 46 & 120.3 \\
Pluronic F-127 & 4.7 & 0.057 & 95.3 & 104.1 \\
\hline
\end{tabular}

A1-fraction component 1; A2-fraction component 2; T1,1 and T1,2-spin-lattice relaxation times.

anions which have stronger influence than the cations [50-54]. For $\mathrm{pH}-5$ and $\mathrm{pH}-9$, the presence of both $\mathrm{Cl}^{-}$and $\mathrm{HO}^{-}$anions in the reaction mixture lower the cloud point of the PEO chains and the critical micellization temperature [50,51], therefore, the solubility of phenolic-resin decrease (salting-out phenomena), hence they cross-link and precipitate faster. These modifications may trigger different interactions between the micelle corona and the phenolresin polymer and in-fine various organization of carbon materials [55]. According to the Hofmeister series and the salting-out strength, the anions used here have the following order $\mathrm{HO}^{-} \gg \mathrm{Cl}^{-}[51,56]$. Therefore, for high $\mathrm{pH}$, dehydration of PEO micelles is induced by $\mathrm{NaOH}$ which significantly reduces the $\mathrm{H}$ bonding interactions and self-assembly between the micelles corona and the polymer. This explains the "separation" of phenolic resin and template and the lost of mesoporosity.

\section{Discussions}

The soft-template approach was combined with the salt template one in order to improve the microporosity of mesoporous carbons. The synthesis conditions allowing to obtain mesoporous materials were inspired from our previous works [13], while in this work the influence of addition of various metallic salts under different experimental conditions was investigated. For $\mathrm{pH}-1$, the nitrogen adsorption/desorption isotherms (Fig. 1) showed no improvement of microporosity by incorporation of $\mathrm{KCl}$ salt in the classical reaction mixture ( $\mathrm{pH}-1 \mathrm{NS}$ ), however, the mesoporosity was affected. Such result suggests the location of $\mathrm{KCl}$ metal salt rather in the proximity of template micelles than in the structure of phenolic resin.

The addition of $\mathrm{NaOH}$ increases the $\mathrm{pH}$ and induces significant modifications of carbon textural and structural characteristics. When raising the $\mathrm{pH}$ up to 5 , the microporosity increases then slightly decreases for higher $\mathrm{pH}(\mathrm{pH}-9)$, while the mesoporosity is gradually lost. The morphology changes (Fig. 2) as well with the $\mathrm{pH}$, from an ordered mesoporous one ( $\mathrm{pH}-1)$ to a worm-like mesoporous ( $\mathrm{pH}-5)$, a smooth microporous one ( $\mathrm{pH}-5)$ and finally to a graphitic-like structure ( $\mathrm{pH}-9)$.

To explain the textural and morphology evolution with the $\mathrm{pH}$, several analysis were conducted on the phenolic resins before carbonization. SAXS analysis (Fig. 8) demonstrated an ordered mesoporous structure of the phenolic resin prepared at $\mathrm{pH}-1$ which is gradually lost with the increase of the $\mathrm{pH}$ up to 9 . The ${ }^{1} \mathrm{H}$ NMR relaxation studies showed only a T1 (Table 3) for $\mathrm{pH}-1$ and $\mathrm{pH}-3$, hence a homogenous monocomponent system composed by the phenolic resin self-assembled with the template via $\mathrm{H}$-bonding interactions is formed. For $\mathrm{pH}-5$ and $\mathrm{pH}-9$, the materials presented two T1, which were associated with a bi-component system, composed of phenolic resin and the pluronic template with limited $\mathrm{H}$-bonding interactions due to the dehydration of PEO segments in basic conditions. These results explain the lost of the mesoporosity with the increase in the $\mathrm{pH}$. For such high $\mathrm{pH}$, the presence of pluronic template is not even required, their textural characteristics being similar as those obtained in the absence of the template (Fig. 7). The graphitization maybe explained by the higher $\mathrm{NaOH}$ quantities inducing better cross-linking and stronger synergetic effects between the $\mathrm{NaOH}$ and/or $\mathrm{KCl}$ and the phenolic resin/template composite.

To understand the development of the microporosity with the increase of $\mathrm{pH}$ (amount of $\mathrm{NaOH}),{ }^{13} \mathrm{C}$ and ${ }^{1} \mathrm{H}$ NMR (Figs. 9 and 10) was employed. Based on the identification of ${ }^{13} \mathrm{C}$ peaks, several reactions pathway mechanisms have been proposed (Eqs. (1)-(3)). Mainly condensation and electrophilic aromatic substitution reactions between the phloroglucinol and glyoxylic acid and/or their derivates take place which leads to the formation of larger polymer molecules where the phloroglucinol aromatic rings are bridged by lactone or ether groups. The increase of the $\mathrm{pH}$ favors the formation of highly substituted phloroglucinol molecules and therefore better cross-linking of phenolic resin. In addition, the ${ }^{1} \mathrm{H}$ spectra NMR (Fig. 10a) evidenced in the case of $\mathrm{pH}-9$ the formation of cations solvated by water (water structures).

The metallic salt and the $\mathrm{NaOH}$ may both play a role on the porosity and on the structural carbon characteristics. The metallic salt act as a porogen, the formation of microporosity being favorised by its dissolution in the carbon network [25,26]. The mechanism is related to dehydration of carbon (removal of oxygen and hydrogen) with the formation of water which leads to pores creation and aromatization of carbon skeleton [57]. When the temperature is increasing the interaction between the carbon and the salt are stronger and the microporosity is significantly improved (Fig. 6). In addition, for higher temperatures than the melting point of the salts, evaporation of metal salt occurs (TGA results, Fig. S8) leading to the development of the mesoporosity as well. $\mathrm{LiCl}$ has the lowest melting point $\left(615{ }^{\circ} \mathrm{C}\right)$, higher quantities of $\mathrm{LiCl}$ are evaporated (Fig. S8) and it results in the highest mesoporous volume (Table 2).

The base, $\mathrm{NaOH}$ also interact with the carbon walls and removes atoms from its lattice and pores may be formed by evolvement of gases such as $\mathrm{CO}_{\mathrm{x}}[58]$.

These two separated mechanism scenarios (salt or base) cannot explain the larger surface areas of carbon materials prepared with $\mathrm{pH}>3$ (between 911 and $1673 \mathrm{~m}^{2} \mathrm{~g}^{-1}$ ). If we consider that the materials synthesized only in the presence of $\mathrm{KCl}$ salt ( $\mathrm{pH}-1 \mathrm{ma}-$ terial) or only in the presence of $\mathrm{NaOH}$ (No salt material) have lower surface area (538 and $109 \mathrm{~m}^{2} \mathrm{~g}^{1}$, respectively), only synergistic effects between the $\mathrm{KCl}$ and $\mathrm{NaOH}$ may be accounted for the improvement of microporosity and of the SSA at high $\mathrm{pH}$.

To explain this synergetic effect, the competition between the salt cation $(\mathrm{K})$ and base cation $(\mathrm{Na})$ for water and aromatic sites in the reaction mixture must be analyzed. The hydration enthalpy of the metals varies in the following way: $\mathrm{Li}>\mathrm{Na}>\mathrm{K}$ (Table 4) which

Table 4

Properties of metals and metal salts [45-47].

\begin{tabular}{|c|c|c|c|c|}
\hline Cation & Ionic radius, $\AA$ & Hydration enthalpy $-\Delta \mathrm{H}, \mathrm{Kcal} / \mathrm{mol}$ & Binding energy $-\Delta \mathrm{H}, \mathrm{Kcal} / \mathrm{mol}$ & Melting point metal chlorides, ${ }^{\circ} \mathrm{C}$ \\
\hline $\mathrm{Li}$ & 0.60 & 122 & 38 & 615 \\
\hline $\mathrm{Na}$ & 0.95 & 98 & 28 & 801 \\
\hline $\mathrm{K}$ & 1.33 & 77 & 19 & 770 \\
\hline
\end{tabular}


allows to assume that in the $\mathrm{KCl}$ system, $\mathrm{Na}^{+}$will be preferentially hydrated by the water molecules compared to $\mathrm{K}^{+}$. However, the mechanism is more complex due to the presence of aromatic molecules in our system (phloroglucinol derived compounds). Such aromatic molecules are known to affect the affinity of the cations vs. water, the cations being more attracted by aromatic molecules than by water through the so called cation- $\pi$ interactions [45,47,59-61]. It has been shown that in aqueous solution, the $\mathrm{K}^{+}$ exhibits significantly higher cation- $\pi$ binding energies than $\mathrm{Na}^{+}$ and $\mathrm{Li}^{+}[45,47]$. This was explained by the fact that the $\mathrm{Li}$ and $\mathrm{Na}$ have high cation- $\pi$ binding energies and high solvation energies (Table 4) which induces high desolvation energy of Li and $\mathrm{Na}$ to bind further to the benzene ring. Hence, it can be proposed that the $\mathrm{K}^{+}$ions are directed mainly towards aromatic rings of phloroglucinol or their substituted derivates, while the $\mathrm{Na}^{+}$ions are more susceptible to hydration by water molecules. Therefore, in the presence of $\mathrm{NaOH}(\mathrm{pH}>3)$ the $\mathrm{KCl}$ is directed towards the phenolic resin "assuming" its role as microporous template while the $\mathrm{NaOH}$ is more directed to the micelles influencing the mesoporosity. As other synthesis were performed also in the presence $\mathrm{NaCl}$ or $\mathrm{LiCl}$ salts, an order of metal biding to the aromatic rings in aqueous solutions containing $\mathrm{NaOH}$ can be proposed: $\mathrm{KCl}>\mathrm{NaCl}>\mathrm{LiCl}$ $[45,47]$.

The salt type influences as well the textural features of the obtained carbons. The surface area and the microporosity increases in the following order, $\mathrm{KCl}>\mathrm{NaCl}>\mathrm{LiCl}$, same order as the binding energies in aqueous medium, while the mesoporosity varies in an opposite manner (Table 2). As proposed by other authors [62], the order of increase in the microporosity maybe also linked with the cation size, i.e., the larger the cation size the higher the surface area. In this work the cation size varies in the following order $\mathrm{K}>\mathrm{Na}>\mathrm{Li}$ (Table 4), therefore in the same way as the SSA (Table 2).

The type of salt induces also alteration of carbon structure (Figs. 4 and 5). The $\mathrm{KCl}$ derived carbon presents no graphitic domain (Figs. 4b and 5), while for $\mathrm{NaCl}$ and $\mathrm{LiCl}$ small graphitic domains are observed (Figs. 4c-f and 5). As report previously [63,64], the thermal treatment of metal/carbon mixtures above the melting point of metal may induce the formation of graphitic nanostructures. This was clearly observed on $\mathrm{LiCl}$ which have low melting point $\left(615^{\circ} \mathrm{C}\right.$, Table 4$)$ compared to $\mathrm{KCl}\left(790^{\circ} \mathrm{C}\right)$ and which graphitized at lower temperatures $\left(750{ }^{\circ} \mathrm{C}\right)$. Therefore, the graphitization/nanostructuration order varies in the same way as the gas binding energy for cation- $\pi$ interactions (Table 4), $\mathrm{Li}>\mathrm{Na}>\mathrm{K}$ and inversely to the melting point.

\section{Conclusions}

Porous carbon materials with various textural and structural characteristics were prepared by a novel soft-salt template synthesis approach and their synthesis mechanism addressed. Various parameters were tuned and their influence on the phenolic resin and carbon characteristics was studied in detail. The increase of reaction mixture $\mathrm{pH}$ using $\mathrm{NaOH}$, induces textural and structural modifications. For $\mathrm{pH}$ up to 5 , a significant improvement in the carbon microporosity but in the detrimental of mesoporosity is obtained. This is accompanied by a morphology change, from mesoporous ordered ( $\mathrm{pH}-1)$ to worm-like structure $(\mathrm{pH}-3)$ and smooth one (pH-5). The ${ }^{13} \mathrm{C}$ and ${ }^{1} \mathrm{H}$ NMR suggest that the mesoporosity lost is caused by the decrease of $\mathrm{H}$-bonding and selfassembly between the phenolic resin and the template via the formation of water structures by dehydration of template PEO moieties due to the strong "salting-out" effect of $-\mathrm{OH}$ ions. For higher $\mathrm{pH}$ (ph-9) the porosity start to decrease and graphene-sheet like morphology is formed.

In addition, several salts were studied $(\mathrm{KCl}, \mathrm{NaCl}$ and $\mathrm{LiCl})$ and proved to have different impact on the carbon textural properties and graphitization. The microporous volume and the surface area varies in the following order $(\mathrm{K}>\mathrm{Na}>\mathrm{Li})$ while the mesoporosity in the opposite way. This trend was explained by a synergetic effect between the salt cations and the Na cation for water and aromatic site but also by the metal salt properties.

The structure changes as well from smooth turbostatic $(\mathrm{KCl})$ to defective graphene-sheet like morphology ( $\mathrm{NaCl}, \mathrm{LiCl})$. The graphitic-like structure formation was explained by the gas-phase binding energies of cations with the aromatic ring which strongly depends on the cation type ( $\mathrm{Li}>\mathrm{Na}>\mathrm{K}$ ).

\section{Acknowledgements}

This work was financially supported by the "Pôle Matériaux et Nanoscience d'Alsace-2013"-France. The authors acknowledge Loïc Vidal, Gautier Schrodj and Jean-Marc Le Meins for their assistance with the TEM, ATG and SAXS analysis.

\section{Appendix A. Supplementary data}

Supplementary data related to this article can be found at http:// dx.doi.org/10.1016/j.carbon.2016.08.011.

\section{References}

[1] S. Candelaria, Y. Shao, W. Zhou, X. Li, J. Xiao, J. Zhang, Y. Wang, J. Liu, J. Li, G. Cao, Nanostructured carbon for energy storage and conversion, Nano Energy 1 (2012) 195-220.

[2] J.C. Ndamanisha, L.P. Guo, Ordered mesoporous carbon for electrochemical sensing: a review, Anal. Chim. Acta 747 (2012) 19-28.

[3] J. Tang, J. Liu, N. Torad, T. Kimura, Y. Yamauchi, Tailored design of functional nanoporous carbon materials toward fuel cell applications, Nano Today 9 (2014) 305-323.

[4] W. Xin, Y. Song, Mesoporous carbons: recent advances in synthesis and typical applications, RSC Adv. 5 (2015) 83239-83285.

[5] B. Yuan, X. Wu, Y. Chen, J. Huang, H. Luo, S. Deng, Adsorption of $\mathrm{CO}_{2}, \mathrm{CH}_{4}$, and $\mathrm{N}_{2}$ on ordered mesoporous carbon: approach for greenhouse gases capture and biogas upgrading, Environ. Sci. Technol. 47 (2013) 5474-5480.

[6] X. Yuan, S.-P. Zhuo, W. Xing, H.-Y. Cui, X.-D. Dai, X.-M. Liu, Z.-F. Yan, Aqueous dye adsorption on ordered mesoporous carbons, J. Colloid Interface Sci. 310 (2007) 83-89.

[7] T. Kyotani, N. Snobe, A. Tomita, Formation of highly orientated graphite from polyacrylonitrile by using a two-dimensional space between montnorillonite lamellae, Nature 331 (1988) 331-333.

[8] J. Lee, S. Han, T. Hyeon, Synthesis of new nanoporous carbon materials using nanostructured silica materials as templates, J. Mater. Chem. 14 (2004) $478-486$.

[9] R. Ryoo, S.H. Joo, S. Jun, Synthesis of highly ordered carbon molecular sieves via template-mediated structural transformation, J. Phys. Chem. B 103 (1999) $7743-7746$.

[10] L. Chuenchom, R. Kraehnert, B.M. Smarsly, Recent progress in soft-templating of porous carbon materials, Soft Matter 8 (2012) 10801-10812.

[11] T.-Y. Ma, L. Liu, Z.-Y. Yuan, Direct synthesis of ordered mesoporous carbons, Chem. Soc. Rev. 42 (2013) 3977-4003.

[12] Y. Meng, D. Gu, F. Zhang, Y. Shi, H. Yang, Z. Li, C. Yu, B. Tu, D. Zhao, Ordered mesoporous polymers and homologous carbon frameworks: amphiphilic surfactant templating and direct transformation, Angew. Chem. Int. Ed. 117 (2005) 7215-7221.

[13] C. Matei Ghimbeu, L. Vidal, L. Delmotte, J-M. Le Meins, C. Vix-Guterl, Catalystfree soft-template synthesis of ordered mesoporous carbon tailored by phloroglucinol/glyoxylic acid environmentally friendly precursors, Green Chem. 16 (2014) 3079-3088.

[14] M. Xie, H. Dong, D. Zhang, X. Guo, W. Ding, Simple synthesis of highly ordered mesoporous carbon by self-assembly of phenol-formaldehyde and block copolymers under designed aqueous basic/acidic conditions, Carbon 49 (2011) 2459-2464.

[15] D. Long, W. Qiao, L. Zhan, L. Liang, Effect of template and precursor chemistry on pore architectures of triblock copolymer-templated mesoporous carbons, Microporous Mesoporous Mater. 121 (2009) 58-66.

[16] S. Tanaka, A. Doi, N. Nakatani, Y. Katayama, Y. Miyake, Synthesis of ordered mesoporous carbon films, powders, and fibers by direct triblock-copolymertemplating method using an ethanol/water system, Carbon 47 (2009) 2688-2698

[17] Y. Huang, H. Cai, T. Yu, X. Sun, D. Zhao, Highly ordered mesoporous carbonaceous frameworks from a template of a mixed amphiphilic triblockcopolymer system of PEO-PPO-PEO and reverse PPO-PEO-PPO, Chem. Asian 
J. 2 (2007) 1282-1289.

[18] Y. Huang, H. Cai, T. Yu, F. Zhang, Y. Meng, D. Gu, Y. Wan, X. Sun, B. Tu, D. Zhao, Formation of mesoporous carbon with a face-centered-cubic Fd3m structure and bimodal architectural pores from the reverse amphiphilic triblock copolymer PPO-PEO-PPO, Angew. Chem. Int. Ed. 46 (2007) 1089-1093.

[19] M. Enterria, F. Garcia-Suarez, A. Martinez-Alonso, J. Tascon, Avoiding structure degradation during activation of ordered mesoporous carbons, Carbon 50 (2012) 3826-3835.

[20] J. Gorka, A. Zawislak, J. Choma, M. Jaroniec, KOH activation of mesoporous carbons obtained by soft-templating, Carbon 46 (2008) 1159-1161.

[21] J. Zhang, Y. Deng, J. Wei, Z. Sun, D. Gu, H. Bongard, C. Liu, H. Wu, B. Tu, F. Schuth, D. Zhao, Design of amphiphilic ABC triblock copolymer for templating synthesis of large-pore ordered mesoporous carbons with tunable pore wall thickness, Chem. Mater. 21 (2009) 3996-4005.

[22] Y. Li, J. Wei, W. Luo, C. Wang, W. Li, S. Feng, Q. Yue, M. Wang, A. Elzatahry, Y. Deng, D. Zhao, Tricomponent coassembly approach to synthesize ordered mesoporous carbon/silica nanocomposites and their derivative mesoporous silicas with dual porosities, Chem. Mater. 26 (2014) 2438-2444.

[23] P. Tripathi, M. Liu, L. Gan, J. Qian, Z. Xu, D. Zhu, N.N. Rao, High surface area ordered mesoporous carbon for high-level removal of rhodamine B, J Mater. Sci. 48 (2013) 8003-8013.

[24] J. Gorka, M. Jaroniec, Hierarchically porous phenolic resin-based carbons obtained by block copolymer-colloidal silica templating and post-synthesis activation with carbon dioxide and water vapor, Carbon 9 (2011) 154-160.

[25] N. Fechler, T.-P. Fellinger, M. Antonietti, "Salt Templating": a simple and sustainable pathway toward highly porous functional carbons from ionic liquids, Adv. Mater. 25 (2013) 75-79.

[26] E. Masika, R. Mokaya, High surface area metal salt templated carbon aerogels via a simple subcritical drying route: preparation and $\mathrm{CO}_{2}$ uptake properties, RSC Adv. 3 (2013) 17677-17681.

[27] N. Bhandari, R. Dua, L. Estevez, R. Sahore, E. Giannelis, A combined salt-hard templating approch for synthesis of multi-modal porous carbons used for probing the simultaneous effects of porosity and electrode engineering on EDLC performance, Carbon 87 (2015) 29-43.

[28] X. Deng, B. Zhao, L. Zhu, Z. Shao, Molten salt synthesis of nitrogen-doped carbon with hierarchical pore structures for use as high-performance electrodes in supercapacitors, Carbon 93 (2015) 48-58.

[29] N. Fechler, S.-A. Wohgemuth, P. Jaker, M. Antonietti, Salt and Sugar: direct synthesis of high surface area carbon materials at low temperatures via hydrothermal carbonization of glucose under hypersaline conditions, J. Mater. Chem. A 1 (2013) 9418-9421.

[30] J. Ludwinowicz, M. Jaroniec, Potassium salt-assisted synthesis of highly microporous carbon spheres for $\mathrm{CO}_{2}$ adsorption, Carbon 82 (2015) 297-303.

[31] L. Roldan, Y. Marco, E. Garcia-Bordejé, Bio-sourced mesoporous carbon doped with heteroatoms $(\mathrm{N}, \mathrm{S})$ synthesized using one-step hydrothermal process for water remediation, Micro. Mesoporous. Mater 222 (2016) 55-62.

[32] S. Zhu, J. Li, C. He, N. Zhao, E. Liu, C. Shi, M. Zhang, Soluble salt self-assemblyassisted synthesis of three-dimensional hierarchical porous carbon networks for supercapacitors, J. Mater. Chem. A 3 (2015) 22266-22273.

[33] J. Jagiello, J. Olivier, Carbon slit pore model incorporating surface energetical heterogeneity and geometrical corrugation, Adsorption 19 (2013) 777-783.

[34] J. Jagiello, J. Olivier, 2D-NLDFT adsorption models for carbon slit-shaped pores with surface energetical heterogeneity and geometrical corrugation, Carbon 55 (2013) 70-80.

[35] M. Pimenta, G. Dresselhaus, M. Dresselhaus, L. Cancado, A. Jorio, R. Saito, Studying disorder in graphite-based systems by Raman spectroscopy, Phys. Chem. Chem. Phys. 9 (2007) 1276-1290.

[36] A.C. Ferrari, Raman spectroscopy of graphene and graphite: disorder, electron-phonon coupling, doping and nonadiabatic effects, Solid State Commun. 143 (2007) 47-57.

[37] A. Ahmed, Methanol effect on color stability and shelf life of phenolic resin compound under acidic conditions, Iraqi J. Chem. Pet. Eng. 10 (2007) 57-63.

[38] Y. Ito, N. Sugimoto, T. Akiyama, T. Yamazaki, K. Tanamoto, Cepaic acid, a novel yellow xanthylium pigment from the dried outer scales of the yellow onion Allium cepa, Tetrahedron Lett. 50 (2009) 4084-4086.

[39] Y. Meng, D. Gu, F. Zhang, Y. Shi, L. Cheng, D. Feng, Z. Wu, Z. Chen, Y. Wan, A. Stein, D. Zhao, A family of highly ordered mesoporous polymer resin and carbon structures from organic-organic self-assembly, Chem. Mater. 18 (2006) 4447-4464.

[40] F. Zhang, Y. Meng, D. Gu, Y. Yan, Z. Chen, T. Bo, D. Zhao, An aqueous cooperative assembly route to synthesize ordered mesoporous carbons with controlled structures and morphology, Chem. Mater. 18 (2006) 5279-5288.
[41] O. Han, Y. Bae, Solid-state NMR study on the structure and dynamics of triblock copolymers P123 remaining in SBA-15 after solvent washing, Bull. Korean Chem. Soc. 29 (2008) 911-912.

[42] E. Rampazzo, R. Voltan, L. Petrizza, N. Zaccheroni, L. Prodi, F. Casciano, G. Zauli, P. Secchiero, Proper design of silica nanoparticles combine high brightness, lack of cytotoxicity and efficient cell endocyrosis, Nanoscale 5 (2013) 7897-7905.

[43] E. Florin, R. Kjellander, J. Eriksson, Salt effects on the cloud point of the poly(ethylene oxide)+ water system, J. Chem. Soc. Faraday Trans. 180 (1984) 2889-2910.

[44] A. Forse, J. Griffin, V. Presser, Y. Gogotsi, C. Grey, Ring current effects: factors affecting the NMR chemical shift of molecules adsorbed on porous carbons, J. Phys. Chem. C 118 (2014) 7508-7514.

[45] R. Kumpf, D. Dougherty, A mechanism for ion selectivity in potasium channels: computational studies of cation-pi interactions, Science 261 (1993) 1708-1710.

[46] A. Stace, Estimating the hydration enthalpies of neutral alkali metal atoms, J. Phys. Chem. 110 (2006) 20742-20744.

[47] D. Dougherty, The cation-pi interaction, Acc. Chem. Res. 46 (2013) 885-893.

[48] P. Alexandridis, V. Athanassiou, S. Fukuda, T. Hatton, Surface activity of poly(ethylene oxide)-block-poly(propylene oxide)-block-poly(ethylene oxide) copolymers, Langmuir 10 (1994) 2604-2612.

[49] H. Heerklotz, A. Tsamaloukas, K. Kita-Tokarczyk, P. Strunz, T. Gutberlet, Structural, volumetric, and thermodynamic characterization of a micellar sphere-to-rod transition, J. Am. Chem. Soc. 126 (2004) 16544-16552.

[50] P. Alexandridis, J. Holzwarth, Differential scanning calorimetry investigation of the effect of salts on aqueous solution properties of an amphiphilic block copolymer (poloxamer), Langmuir 13 (1997) 6074-6082.

[51] E. Leontidis, Hofmeister anion effects on surfactant self-assembly and the formation of mesoporous solids, Curr. Opin. Colloid \& Interface Sci. 7 (2002) 81-91.

[52] C. Matei Ghimbeu, J. Le Meins, C. Zlotea, L. Vidal, G. Schrodj, M. Latroche C. Vix-Guterl, Controlled synthesis of NiCo nanoalloys embedded in ordered porous carbon by a novel soft-template strategy, Carbon 67 (2014) 260-272.

[53] S. Sun, C. Matei Ghimbeu, R. Janot, J.M. Le Meins, A. Cassel, C. Davoisne C. Masquelier, C. Vix-Guterl, One-pot synthesis of LiFePO4-carbon mesoporous composites for Li-ion batteries, Microporous Mesoporous Mater. 198 (2014) 175-184.

[54] D. Zhao, Q. Huo, J. Feng, B. Chmelka, G. Stucky, Non-ionic triblock and sta diblock copolymer and oligomeric surfactant syntheses of highly ordered, hydrothermally stable, mesoporous silica structures, J. Am. Chem. Soc. 120 (1998) 6024-6036.

[55] S. Schlienger, C. Ducrot-Boisgontier, L. Delmotte, J.-L. Guth, J. Parmentier History of the micelles: a key parameter for the formation mechanism of ordered mesoporous carbons via a polymerized mesophase, J. Phys. Chem. C 118 (2014) 11919-11927.

[56] W. Kunz, J. Henle, B. Ninham, Zur Lehre von der Wirkung der Salze' (about the science of the effect of salts: Franz Hofmeister's historical papers, Curr. Opin. Colloid Interface Sci. 9 (2004) 19-37.

[57] Z. Hu, E.A. Vansant, New composite adsorbent produced by chemical activation of elutrilithe with zinc chloride, J. Colloid Interface Sci. 176 (1995) $422-431$.

[58] F. Rodriguez-Reinoso, M. Molina-Sabio, Activated carbons from lignocellulosic materials by chemical and/or physical activation: an overview, Carbon 30 (1992) 1111-1118.

[59] J. Sunner, K. Nishizawa, P. Kerbale, Ion-solvent molecule interactions in the gas phase. The potassium ion and benzene, J. Phys. Chem. 85 (1981) $1814-1820$

[60] O. Cabarcos, C. Weinheimer, J. Lisy, Size selectivity by cation -pi interactions: solvation of $\mathrm{K}^{+}$and $\mathrm{Na}^{+}$by benzene and water, J. Chem. Phys. 110 (1999) 8429-8435.

[61] O. Cabarcos, C. Weinheimer, C. Lisy, Competitive solvation of $\mathrm{K}+$ by benzene and water: cation-pi interactions and pi-hydrogen bonds, J. Chem. Phys. 108 (1998) 5151-5154.

62] K. Okada, N. Yamamoto, Y. Kameshima, A. Yasumori, Porous properties of activated carbons from waste newspaper prepared by chemical and physical activation, J. Colloid Interface Sci. 262 (2003) 179-193.

[63] A. Kamali, D. Fray, Molten salt corrosion of graphite as possible way to make carbon nanostructures, Carbon 56 (2013) 121-131.

[64] J. Sure, A. Shankar, S. Ramya, U. Mudali, Molten salt corrosion of high density graphite and partially stabilized zirconia coated high density graphite in molten LiCl-KCl salt, Ceram. Int. 38 (2012) 2803-2812. 